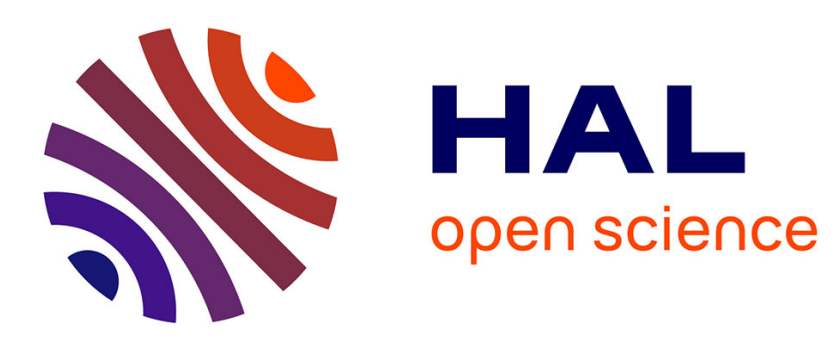

\title{
Definition and identification of small RNA sponges: Focus on miRNA sequestration
}

Mélodie Migault, Emmanuelle Donnou-Fournet, Marie-Dominique Galibert, David Gilot

\section{To cite this version:}

Mélodie Migault, Emmanuelle Donnou-Fournet, Marie-Dominique Galibert, David Gilot. Definition and identification of small RNA sponges: Focus on miRNA sequestration. Methods, 2017, 117, pp.3547. 10.1016/j.ymeth.2016.11.012 . hal-01502131

HAL Id: hal-01502131 https://hal-univ-rennes1.archives-ouvertes.fr/hal-01502131

Submitted on 5 Apr 2017

HAL is a multi-disciplinary open access archive for the deposit and dissemination of scientific research documents, whether they are published or not. The documents may come from teaching and research institutions in France or abroad, or from public or private research centers.
L'archive ouverte pluridisciplinaire HAL, est destinée au dépôt et à la diffusion de documents scientifiques de niveau recherche, publiés ou non, émanant des établissements d'enseignement et de recherche français ou étrangers, des laboratoires publics ou privés. 


\title{
Definition and identification of small RNA sponges: focus on miRNA sequestration
}

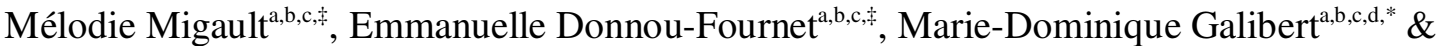 \\ David Gilot ${ }^{\mathrm{a}, \mathrm{b}, \mathrm{c}, *}$
}

${ }^{a}$ Centre National de la Recherche Scientifique (CNRS) Unité Mixte de Recherche (UMR) 6290, Institut de Génétique et Développement de Rennes, France

${ }^{\mathrm{b}}$ Université de Rennes 1, Rennes, France

${ }^{\mathrm{c}}$ Cancer Research Association (ARC) Labelled Team

${ }^{\mathrm{d}}$ Department of Medical Genomic, Rennes University Hospital, Rennes, France.

Co-first authors

\begin{abstract}
*Address:
CNRS UMR6290, IGDR, Université de Rennes 1, 2 avenue Pr Léon Bernard, 35043, Rennes, France. Fax: +33 (0) 223234478

E-mail addresses: mgaliber@univ-rennes1.fr or david.gilot@univ-rennes1.fr
\end{abstract}

\begin{abstract}
Targeting RNAs appears as an important opportunity to modulate biological processes. Here, we overviewed critical parameters implied in RNAs competition to bind small RNAs. These competitions influence small RNA availability and thereby gene expression and cell fate. We focused on the ability of RNAs to sequester small RNA, mainly the microRNAs (miRNAs) and proposed experimental workflows to demonstrate the existence and activity of RNA sponge. From this basic science, we detailed tailored oligonucleotides, developed to challenge the binding of small RNA. In vitro and in vivo, these tailored oligonucleotides efficiently restore small RNA activity by preventing their sequestration on RNA-sponges.
\end{abstract}

\section{Introduction}

miRNAs are a class of short (approximatively $22 \mathrm{nt}$ ) noncoding RNAs (ncRNAs) that mediate post-transcriptional gene expression regulation. Part of an RNA-induced silencing complex (RISC), single-stranded miRNA hybridizes specifically to mRNA targets, inhibits translation and mediate the degradation of the targeted RNA [1-5]. The timing of this process has not been clearly established yet, and may be influenced by many parameters [6].

The gold standard miRBase database has listed about 2,500 human miRNAs and miRNAs are predicted to affect the expression of about 50\% of coding RNA [7]. These data suggested a major role for miRNA in regulating gene expression. However loss of function of 
a miRNA has modest phenotypic effect. Less than $10 \%$ of knock out mice for evolutionary conserved miRNAs gives rise to developmental or abnormal embryonic phenotypes [8] although they may appear in sensitized backgrounds or under stress. Similar findings have been reported in $C$. elegans $[9,10]$ and in plants [11]. Added to the generally weak posttranscriptional effect of miRNA on its targets (5-30\%) [12], these results led to the presentation of miRNAs as cellular actors responsible for fine tuning of RNA expression levels.

Abnormal miRNA activity has been linked to numerous diseases [13] and over the last decade, the critical role of miRNA in regulating biological processes has fostered interest in how miRNA binds to and specifically interacts with miRNA response elements (MREs). Pioneering works have shown how MREs may compete for binding to a common miRNA [14-17], emphasizing the importance of determining the proportion of active miRNA per cell [18]. miRNA activity could be reduced using synthetic oligonucleotides (such as antimiRNA) or by introducing synthetic constructs that expressed exogenous MREs (exogenous miRNA sponges) [17-20]. Experiments from plants, mammals and prokaryotes clearly demonstrated that endogenous RNAs compete to bind small RNAs (competing endogenous RNA or target mimicry) (Table 1) [14,21-25]. These competitors bind transiently the miRNA since the miRNA generally induced the RNA decay. Recently, a new class of endogenous competitors, allowing long-term binding (sequestration), has been described (endogenous miRNA sponges RNAs such as circular RNAs (circRNAs)) [26-28]. Indeed, a reduction in functional miRNA, as exemplified by miRNA sequestration, moderates miRNA-dependent mRNA decay. Altered mRNA decay promotes abnormal gene expression, which may ultimately lead to pathological processes [13]. Understanding the underlying mechanisms that define functional miRNAs is thus mandatory to explain biological processes and to propose new therapeutic options. In this review, we proposed experimental workflows to demonstrate the existence and the activity of endogenous miRNA sponges.

\section{2. miRNA Targets}

The post-transcriptional effect of a miRNA on a target varies according to numerous parameters, including the miRNA expression level, the MRE sequence, the number of MREs per RNA molecule and per cell and the accessibility to these MREs (determined at least by RNA's secondary structures and RNA binding proteins (RBPs)) [29,30]. Currently, miRNA quantification is easily achievable by miRNA sequencing (miRNA-Seq) or quantitative PCR. In contrast, the identification of the exact base-pairing between a miRNA and its targets is difficult and thus matter of debate. Many methods have been recently developed to catch these miRNA-MREs contacts. It requires RISC immunoprecipitation (IP) experiments followed by high-throughput analysis of the RNA targets [31-35]. It clearly appeared that miRNA and targeted RNAs can interact through different hybridization manner [33,36-40]. Indeed, as proven by different teams, base-pairing interaction between miRNA and RNA targets is not always limited to the seed regions of miRNAs (nucleotides 2-7). Moreover, the recent meta-analysis performed by Bartel and collaborators confirmed the existence of noncanonical sites that they named non-canonical MREs [36]. They classified these noncanonical MREs as non-functional because they do not exhibit signs of mediating mRNA decay, nor signals for miRNA-dependent evolutionary conservation. Different studies also proposed that the non-canonical MREs represent between 50 and $75 \%$ of a cell's MREs $[33,36,41]$. It is important to keep in mind that 3'-UTR of mRNAs are not the sole targets of miRNAs. Long noncoding RNAs (lncRNAs) and RNAs encoded by pseudogenes also efficiently bind miRNAs [42,43]. Experiments determining the target site abundance (TSA) 
highlighted both, the variety of MREs and the RNAs targeted by miRNAs $[18,36,44,45]$. It is interesting to note that the experiments designed to identify binding sites of RBP led to similar conclusions. For example, canonical and non-canonical binding sites of $\mathrm{HuR}(\mathrm{Hu}$ antigen R - ELAVL1) have been identified and HuR binding on the RNAs is not necessary correlated with a modulation of their expression levels $[35,46,47]$. As for miRNAs, this RBP binds other RNAs than mRNA [48]. These different observations raised many questions: Are MREs of different RNAs in competition to bind a limited pool of miRNAs? Do non-canonical MREs constitute a miRNA-reservoir?

In 2014, Bosson and collaborators addressed the MREs competition issue. They performed Argonaute iCLIP experiments (individual-nucleotide resolution UV-crosslinking and immunoprecipitation) [49,50] followed by absolute quantification of miRNAs and mRNAs to quantitatively assess miRNA-regulation genome-wide. Taking in consideration only messenger RNAs and canonical MREs, this study demonstrated that the total amount of 6/7/8-mer mRNA targets surpass miRNA concentration for almost all miRNA families. Similarly, Denzler and collaborators (2014) reported that the abundance of miR-122 target in primary hepatocytes is above miR-122 levels, despite the high expression level of miR-122 [45]. These two studies suggest that TSA is at least equal or higher than miRNA concentrations, which may lead to the speculation that target sites may compete for the binding of miRNA. And indeed, Bosson and collaborators [18] revealed that endogenous miRNA families were susceptible to competition in contrast to Denzler and collaborators [45].

\section{3. miRNA Response Elements Competition}

The idea that MREs could compete to bind the same pool of miRNAs is not novel. In 2007, two major studies demonstrated this competition in two models (plant and mammal cells) $[14,17]$.

Ebert and collaborators tuned miRNA activity in mammal cells with artificial DNA constructs, named "microRNA sponges" [17,51]. These artificial inhibitors are exogenous transcripts, expressed from strong promoters, with multiple binding sites to a microRNA of interest. The strategy with these artificial inhibitors was to establish a competition between the exogenous and endogenous MREs. Artificial sponges were successful in reprogramming gene expression in vitro [17,52] and in vivo [20] by sequestering specific miRNAs. The competition is improved when several MRE copies are present in each sponge molecule, thereby adsorbing the maximum of miRNAs in each cell [19,51]; and by increasing the expression of these synthetic construct using viral transduction of mammal cells [53].

The first natural miRNA sponge has been identified in Arabidopsis thaliana by Franco-Zorilla and colleagues and was defined as "target mimicry" [14] (Table 1). Note that in plants, most miRNAs show almost perfect complementary with their target, as small interfering RNA (siRNA). In addition, they bring about target mRNA cleavage, which explains the important post-transcriptional effects of miRNA in this model, with strong decrease in proteins [54]. When overexpressing the Induced by Phosphate Starvation 1 (IPS1) RNA, which presents a sequence partly complementary (1 mismatch) to the phosphate starvation-induced miRNA miR399, Franco-Zorilla and collaborators saw a loss-of-function phenotype. They showed that IPSI is not cleaved but instead sequesters miR399, leading to the derepression of at least one of the miR399 targets, the Phosphate 2 mRNA coding PHO2 (Fig. 1.). Overexpressing a mutant form of IPS1 fully complementary to miR399 does not upregulate anymore $P H O 2$, since IPS1 is degraded by miR399, which in turn degrades $P H O 2$. They confirmed this observation by replacing miR399-complementary motif of IPSI by 
another miRNA motif [14]. These data showed for the first time that competition is possible between natural MREs sequence leading to altered miRNA activity and to a specific phenotype. It is important to underscore the term "natural" MRE. Indeed, in contrast to the synthetic sponges developed by Ebert and collaborators, here the MRE sequence used to modulate miR-399 activity is the IPS1 RNA sequence.

In these two studies, the miRNA sponges have been overexpressed using a strong promoter to reach a high level of these MREs. The goal is indeed to achieve an efficient competition between endogenous and overexpressed MREs in order to derepress the endogenous targets of its cognate miRNA. Interestingly, miRNA target competition by sponges occurs in a threshold-like manner [55] similar to other biological systems of molecular titration [56-58].

The competition between endogenous MREs of different RNAs in the same cell has been highlighted in 2011 by the works of P. P. Pandolfi's group (as competing endogenous RNA, ceRNA) in mammals [16,23-25,43] (Table 1). In other words, P. P. Pandolfi proposes that expression levels of RNAs in competition for a miRNA are co-regulated [16,59]. This had earlier been proposed by H. Seitz [15]. Nevertheless, the activity of several ceRNAs is still controversial in mammals $[42,60]$, since the competition mechanism has only been partly explained.

The main criticisms focus on stoichiometry. The concept is indeed based on the ability of RNA $\alpha$ to compete with RNA $\beta$ (both expressing similar MREs for a given miRNA) but having different expression levels $(\alpha>\beta$ measured in copies per cell). The silencing of RNA $\alpha$ releases sufficient miRNA to target and silenced RNA $\beta$. However, the effect of the opposite scenario is less intuitive (silencing RNA $\beta$ when $\alpha>\beta$ ). Indeed, if we speculate that there are 100 copies per cell of RNA $\beta$ and 500 for RNA $\alpha$, both being able to bind respectively 100 and 500 copies of the same miRNA; and if 100 miRNAs are freed after RNA $\beta$ knock down (KD), only 100 of the 500 copies of RNA $\alpha$ should be affected by this miRNA shift, causing only a weak decrease in RNA $\alpha$ expression. But, in the case of the PTEN ceRNA network (ceRNET), all of the highly expressed mRNAs are affected when the weakly expressed ones are inhibited by RNA interference (RNAi) [23-25,61]. Many have questioned the methodology, notably the siRNAs used [45,60]. It is often possible to find short complementary regions between siRNA and other RNA targets, causing siRNA offtarget effects [62]. In the case of PTEN ceRNA network, the off-target effect hypothesis is credible but unlikely, as the authors used multiple siRNAs per target.

Even if these results are quite surprising, data obtained from other models illustrate RNAs competition to bind small RNAs (miRNAs). Low expressed viral RNA can compete with eukaryotic RNAs to bind miRNA via the same MREs. In 2010, J.A Steitz's group demonstrated that the genetic material of Herpesvirus saimiri changes host cell's gene expression by binding cellular miRNA [63]. In infected T cells, the viral non-coding HSUR1 RNA binds miR-27 and induces its degradation. This leads to the increase of miR-27 target genes. Another example was recently strengthened by the study of Hepatitis C Virus (HCV) during its viral RNA replication phase, highlighting the binding of miR-122 to virus RNA [64]. miR-122 not only binds to the 5'-UTR of the low expressed $H C V$ RNA but it stabilized the cell's viral RNA [65]. Here again, the miRNA-viral RNA bond induces a change in expression of the cellular RNAs normally repressed by this miRNA (Fig. 1.). The list does not end with these two viruses. Authors suggested that virus may evolve, either to exploit competitive viral and host RNA (cvhRNA) networks, or to avoid miRNA targeting for optimal fitness within the host [66].

What do these virus-host studies teach us about competition mechanism? An important point to consider is the presence of canonical sites on viral RNA. Usually, this type 
of site in mammals induce the degradation of target RNAs in response to miRNA binding [36]. However, it is the opposite in HCV: miR-122 stabilizes the viral RNA [64]. Two canonical miR-122 sites have been identified. The miRNA hybridizes with the region complementary to the seed sequence and also with part of the 3' section of the miR-122. Only the central part of miR-122 does not hybridize with its target. For Herpes RNA and miR-27, there are 15 complementary nucleotides [63]. Interestingly, miR-27 binds to one side of the stem, thus abrogating the viral RNA's stem-loop secondary structure. Meanwhile, in HCV, miR-122 probably stabilizes the 5' part of the viral RNA's secondary structure. To conclude, these investigations in viruses confirmed that a low expressed RNA can be an efficient ceRNA and draw our attention to two crucial issues: RNA secondary structures and the exact sequences bind by miRNA.

A second recurrent objection against the ceRNA theory is that there is no evidence in animal. Recently, an in vivo study confirmed that RNA competition is achievable in transgenic mice [67]. Mice engineered to overexpress either the full-length murine B-Raf pseudogene Braf-rs1 or its pseudo CDS or 3'-UTR develop an aggressive malignancy resembling human diffuse large B cell lymphoma. The authors proposed that Braf-rs1 elicit its oncogenic activity, at least in part, as ceRNAs by elevating BRAF expression and MAPK activation in vitro and in vivo. However, Denzler and collaborators failed to modulate gene expression through a ceRNA effect by modifying the miRNA TSA, in contrast to Bosson and collaborators $[18,45]$. In mice, Denzler and collaborators. achieved huge expression of a miR122-binding target (AldoA mRNA) to derepress the mRNAs regulated by miR-122. They found that $\sim 150,000$ miRNA-binding sites were required to derepress mRNA targets of miR122. J.A. Broderick and P.D. Zamore recalled that no single mRNA reaches such a high level in vivo and proposed that examples of ceRNAs in normal cells are likely to be rare at best [60]. Moreover, they anticipated that ceRNA will be among the most abundant RNAs in the cell or contain dozens of binding sites for a single miRNA species as described for circRNAs (CDR1as/CiRS-7, SRY \& circHIPK3) [26,28,68].

To conclude, the controversy is mainly based on results obtained in mice. The controversy could be resolved by using knockout experiments instead of overexpression. Moreover, the ceRNA experiments are mostly based on canonical MRE identified in silico (e.g. by Targetscan) on messenger RNAs $[69,70]$. However, other RNAs (and other MREs) have been described to compete with mRNA to bind miRNA. Among them, certain ncRNAs such as lncRNAs, RNAs from pseudogenes and circRNAs are efficient competitors [23,26$28,67,68,71]$. Until now, it is quite difficult to identify canonical MRE on these ncRNAs. For non-canonical MRE, no algorithm predicts such sites; researchers have to demonstrate, one by one, the physical miRNA binding on these sites in vivo. Thus, a better understanding of the ceRNA mechanism requires to include underestimated parameters: ncRNAs, non-canonical MREs, quantitative expression levels of RNAs (miRNAs, mRNAs and ncRNAs), the accessibility of the MRE (modulated at least by RBPs and secondary structures) and the consequence of the miRNA binding on a MRE (RNA decay or not).

\section{4. miRNA Sequestration}

Out of the ceRNA field, it is quite difficult to appreciate what is the difference between a ceRNA and a miRNA sponge. A ceRNA binds at least one miRNA on canonical MRE but the contact is transient since the miRNA commonly induced the RNA decay. Nonetheless, several studies clearly showed that miRNA binding on MRE is not always correlated to RNA decay $[40,72,73]$. As depicted above, the Bartel's group showed that non- 
canonical MREs do not exhibit signs of mediating mRNA decay despite a miRNA binding [36]. Several studies demonstrated that miRNA can also stabilize RNAs or viral RNAs [74]. These data support the concept that these miRNAs are sequestered on RNA since they are no longer free to bind their targets and induce RNA decay. On HCV RNA, canonical MREs sequester miR-122, suggesting that other parameters directing the RNA decay are missed. In addition, a handful of circRNAs are described to bind miRNA on canonical MREs without undergoing RNA decay (probably due to their circular shape) [26-28,75]. The circRNA, CDR1as, an antisense transcript of the cerebellar degeneration-related protein 1 gene, contains 63 evolutionarily conserved binding sites for miR-7. Even if theses events seem to be rare [75], they exist and are very interesting to better understand the miRNA-induced RNA decay. Apart the miRNA sequestration, miRNA activity can also be reduced via the degradation of the miRNA. This process, the target RNA-directed miRNA degradation (TDMD) [76,77], has been previously observed to occur naturally during viral infection. This phenomenon requires a highly complementary target with the miRNA like the HSUR1 RNA and miR-27 have [63].

To conclude, in addition to circRNAs and ceRNAs, we proposed to create a new class of endogenous RNA sequestering miRNA, the spRNA for endogenous sponge RNA. spRNAs display non-canonical MREs that prime long-term miRNA binding (sequestration) (Table 1). Since spRNA display non-canonical MRE with low affinity for miRNA (compared to canonical MRE), it is likely that spRNA will be among the most abundant RNAs in the cell or contain several binding sites to derepress mRNAs normally targeted by this miRNA. To date, no algorithm is available to predict them. To facilitate the understanding of this classification, we propose a table recapitulating the differences between RNAs and their capabilities to bind miRNAs (Table 1).

\section{Lessons from small RNA sequestration in prokaryotes}

In prokaryotes, there is no miRNA but other small regulatory RNA (sRNA - 50 to 500 nt long) that control gene expression and cell fate. Several sRNAs have imperfect, short complementarities with their targets. In addition, some need the help of a chaperone protein. In this last situation, the Sm-like Hfq protein facilitates the interaction between these two bacterial RNAs in order to eventually disrupt the target through RNAse E activity (this way of functioning is similar to the one mediated by the RISC complex). These small RNAs are known to be involved in a wide range of cellular functions that range from iron metabolism to the virulence of pathogenic bacteria [78-80]. In 2009, separate studies demonstrated the functioning of the first sRNA decoy in Escherichia coli and Salmonella enterica [81-84] (Table 2). The constitutively expressed ChiX sRNA binds the polycistronic chiP mRNA (that encodes chitoporin) and the $c h b$ operon ( $c h b B C A R F G)$ mRNA to repress their expression. When chitobiose, a chitosugar by-product, is present, the chb operon's transcription strongly increases and bypasses the ChiX repression. Moreover the $c h b$ mRNA allows the ChiX degradation, by acting as a decoy, and the derepression of chiP mRNA. A similar mechanism has been characterized with a 3'-UTR-derived RNA fragment acting as a GcvB decoy, called SroC [85]. GcvB sRNA participates to its own degradation by inducing the gltIJKL mRNA decay, which triggers SroC production. By this way, the GcvB targetome is derepressed thanks to a fine-tuning mechanism. (Table 2)

As described in eukaryotes, RNA sequestering sRNA as spRNA are also present in prokaryotes. This can be illustrated with the GcvB sRNA. In enterohemorrhagic Escherichia coli, the AgvB sRNA can sequesters GcvB without degrading it [86] (Table 2). It is important to note that AgvB is bacteriophage-encoded, meaning that as viral RNA, sRNA and miRNA 
availability is impacted by exogenous binding sites introduced by bacteriophages and viruses. Recently, Lalaouana and collaborators demonstrated that a 3' external transcribed spacer (ETS) in a pre-tRNA transcript ( $3^{\prime}$ ETS $^{\text {LeuZ }}$ ) acts as a sponge by sequestering two sRNAs (RyhB and RybB) [22] (Table 2). They clearly showed that 3'ETS ${ }^{\text {LeuZ }}$ is able to prevent RhyB from regulating its targets, confirming results obtained with miRNA sponge in mammals. Moreover, this natural sponge generates a threshold response, which discriminates target mRNAs recognized by sRNA with strong affinity from those with lesser affinity. These observations are in accordance with other studies about the threshold $[18,55,56,72,87]$. The source of physiological sponges in bacteria seems not restricted to ETS and 3'-UTR fragments since internal transcribed spacers (ITS) could also act as sRNA sponges [22]. This sponge diversity is also retrieved in mammals. In conclusion, in prokaryote field, the RNAs competition to bind small RNA is well-accepted. One of the most challenging tasks in the sRNA field is to characterize the sRNA targetome also named TSA in mammals. Recently, Melamed and collaborators developed the RIL-seq methodology (RNA interaction by ligation and sequencing) to identify interactions involving Hfq-associated sRNAs [88]. This methodology looks like Argonaute immunoprecipitation in mammals (CLIP-Seq and related methodologies) [32]. In Escherichia coli, they uncovered an extensive network of interactions involving RNA pairs showing sequence complementarity. Interestingly, the comparison of the sRNA interactome under various conditions revealed changes in the sRNA repertoire as well as substantial re-wiring of the network between conditions. The next step is thus to decipher the true targets and sRNA decoys. This knowledge is important because disabling the RNAs competition to bind sRNA affects bacterial fate such as bacterial growth for GcvB $[80,85]$. Altogether, these data demonstrate the physiological importance of such competition in bacteria as recently described in transgenic mice [67].

\section{Demonstrating the existence of a miRNA sponge}

\subsection{How can miRNA sequestered on a candidate sponge be experimentally identified?}

It is not usual to postulate that an RNA is a miRNA sponge. However, after an overview of ceRNAs and miRNA sponges literature, different cases are identified. The first situation is an mRNA encoding protein involved in an identified cellular process and the loss of the mRNA impairs this process. The rescue experiments of KO cells with a mutated mRNA (noncoding for the protein) could indicate a sponge activity or other functions (reviewed in $[43,89]$ ). The second situation includes the noncoding RNAs (pseudogenes, lncRNAs, antisense RNAs, fragment of RNAs). Usually, researchers modify expression levels of such RNAs to identify their functions using $\mathrm{KO}$ and/or overexpression experiments [90]. By this way, they might identify miRNA. The last situation includes studies in which they look for ceRNA or miRNA sponges without a priori. It is typically genome-wide studies performed in vitro or in vivo or in silico $[25,70,87]$.

Since it exists different situations to identify miRNA sponges, we proposed a decision tree to choose appropriate methodologies (Fig. 2). 


\subsubsection{MS2-RIP}

If you have a limited number of candidates, one robust method is to fuse your RNA of interest with a tag RNA like the MS2 hairpin motif from the bacteriophage of the same name [91]. The idea is to use RNA as a bait for miRNA immunoprecipitation and quantification. For this, you also need the expression of a protein recognizing the RNA-MS2 motif, like the MS2 protein fused to the GFP protein (MS2-GFP) [92]. An immunoprecipitation is done to purify the fusion RNA-MS2 complex using an anti-GFP antibody. An MS2-GST protein (MS2 protein fused to the Glutathione S-transferase protein) can also be used, instead of the MS2-GFP one, to pull-down the fusion RNA-MS2 complex through sepharose beads paired with GSH (MS2-TRAP) [93]. In addition, an MS2-MBP protein (MS2 protein fused to the Maltose Binding Protein) immobilized on an amylose resin can be employed to avoid the overexpression of the fusion protein into the cell [94,95]. After many washes and an elution of the associated-miRNAs, the identification and quantification phases have to be done. Several miRNA quantification techniques are available and easy to use [96]. The miRNA-Seq method is particularly suited to the identification of purified RNAs that are well- or not so well-annotated

Advantages: It is cheap, and the overexpression of the RNA-MS2 allows to collect a large amount of high quality miRNA. Mutants, deleted of the MRE, can be used to confirm the MRE/miRNA contact.

Disadvantages: Depending on its size, it could be difficult to overexpress the entire RNA. Therefore, the risk is to lose certain parameters such as secondary structures or RBP binding sites. In mammals, the MS2-RIP and MS2-TRAP approaches are based on the overexpression of two participants: the fusion RNA (and the MS2 protein). Thus it is theoretically possible to generate false positive with the binding of miRNA that would not be bind this RNA under physiological conditions (as with the normal sponge expression).

Potential issues: Crosslinking may be necessary to fix the proteins to the fusion RNA, thus better preserving the miRNA docking during immunoprecipitation or pull-down and multiple washes. This is a crucial point for weakly expressed miRNA but with potential drawbacks (false positive) due to the formation of macrocomplexes.

\subsubsection{Biotinylated oligos}

When you have a sponge candidate, an alternative approach to MS2-RIP can be used. It is based single-stranded short biotinylated oligonucleotides which are complementary to the studied RNA sponge. This technique is called the RNA Antisense Purification (RAP) method [97]. Briefly, cells are crosslinked and lysed. The short fragments (named tiling oligos) are designed to hybridize with a unique region (not found in other RNAs), covering the largest possible area on the RNA to increase purification efficiency. After the capture using streptavidin beads, miRNA identification is performed by strand-specific RNA sequencing. It is particularly suited for the identification of purified RNAs that are well- or not so wellannotated, such as IncRNA. The last step consists to identify the MREs using webtools such as TargetScan or RNAHybrid [36,98].

Advantages: This is a robust method due to the very high affinity and specificity of the biotin-streptavidin system. 
Disadvantages: The design is not always easy for RNA from highly conserved families. miRNA enrichment is limited since biotinylated oligos can only associate with the endogenous sponge. It can be difficult to detect miRNA afterwards.

Potential issues: Requires fixing cellular proteins with formaldehyde. This step could generate false positives by forming macrocomplexes.

\subsection{3. iCLIP and related methodologies}

If you have no idea about the identity of the RNA sponge, the best strategy is to used a genome-wide methodology such as iCLIP (individual-nucleotide resolution CLIP) [49,99]. It consists to perform Argonaute immunoprecipitation after UV-crosslinking [49] in order to identify miRNA-RNAs contacts at individual-nucleotide resolution. The RNA sequencing reveals the identity and the proportion of the miRNA-RNA pairs (see recent review [50]). Several alternative methods exist, including CLIP-Seq (cross-linking immunoprecipitation with sequencing) [100]; PAR-CLIP (photoactivatable ribonucleoside-enhanced CLIP) [101]; CLASH (cross-linking ligation and sequencing of hybrids) [33]; and CLEAR-CLIP (covalent ligation of endogenous Argonaute-bound RNA-CLIP) [31]. These data should be associated to an absolute quantification of miRNAs and RNAs to quantitatively assess miRNA-RNA interactions genome-wide [18]. Quantifications of RNAs and miRNAs can be done using RNA sequencing.

In fine, this pipeline should determine a list of RNAs and their associated-miRNAs. Moreover, this approach should categorize the MRE-miRNA base-pairing (canonical or not). In contrast to Bosson and collaborators, it seems very important to keep all RNAs and not to focus on mRNAs.

Advantages: Very comprehensive because it takes into account non-canonical MREs and all RNAs. The approach also considers all of the actors in controlling MRE accessibility: RBPs, secondary structures, miRNAs competition, etc.

Disadvantages: There are many techniques and bioinformatic analyses, which are not standardized from one lab to the next.

Potential issue: Researchers have to pay attention to the choice of the method for miRNARNA duplex analyzes. A comparison of these different techniques that underline their advantages and drawbacks had already been published [102].

\subsection{How can the sponge be experimentally identified from the candidate miRNA?}

\subsubsection{Biotinylated miRNA}

The easiest strategy is the synthesis of biotinylated miRNA (3'end) to be transfected into the cells of interest [103]. Quickly thereafter, cells are crosslinked and lysed, streptavidin beads are used to capture the biotinylated miRNA and the associated RNA. After stringent washes, elute the associated RNAs and analyze them as per RAP method [97]. In vitro capture of miRNA target can also been performed by pulling down a cell lysate through the single-strand biotinylated miRNA directly coupled with the streptavidin support (beads or 
surface) $[104,105]$. The purified RNAs can be identified using several methods including RNA-Seq.

Advantages: This method includes the detection of both canonical and non-canonical MREs.

Disadvantages: miRNA overexpression is different than endogenous miRNA quantities and this can induce non-physiological interaction.

Potential issues: Crosslinking can provide false positives.

\subsection{How to confirm that a candidate RNA is a miRNA sponge?}

After the identification of miRNAs/RNAs interactions, the next steps involve to prove that the RNA of interest has a miRNA sponge activity.

\subsubsection{Sponge's resistance to miRNA-induced decay}

To perform a long-term miRNA sequestration, the putative sponge should be resistant to RNA decay induced by an associated miRNA. This can be evaluated by overexpressing the candidate miRNA and measuring the putative sponge's expression. For a coding RNA, no decrease of RNA and protein levels should be observed for a sponge. As control, known targets of the candidate miRNA must be downregulated.

To go further, the non-canonical MRE of the putative sponge can be replaced by a canonical one and a decrease of the mutant sponge expression should be observed when the candidate miRNA is overexpressed. This approach can be done using miRNA sensors. They are made by fusing the luciferase-encoding RNA with canonical or non-canonical MREs (Fig. 3.) The synthetic miRNA should induce the degradation of the fused RNA in presence of canonical MREs, thereby limiting the synthesis of luciferase protein and the luciferase enzyme activity [106]. Contrariwise, effect of miRNA will be weak (even no effect at all) on the sensor containing non-canonical MREs. Selective mutations can be done to determine the direct binding of the miRNA to the sensor (MRE). Rescue experiments can be done by using synthetic miRNA containing complementary bases to mutations.

Advantages: The miRNA sensors (wild type \& mutated) confirm the direct interaction between the sponge and the miRNA.

Disadvantages: Other RNA interactants are ignored such as other miRNAs and RBP since miRNA sensors contain short RNA fragments from the sponge.

Potential issue: The MRE's sequence has to be known in order to mutate it. For noncanonical MREs, RNAhybrid software can be used.

\subsubsection{Sequestered miRNAs and secondary targets}

After the demonstration of the miRNA-RNA sponge complex, it is essential to demonstrate that miRNA sequestration occurred in vivo. Two solutions could be envisaged: an overexpression of the sponge to derepress the endogenous targets of this miRNA, or the 
$\mathrm{KD}$ of the sponge to redirect miRNA on its targets (RNA decay). In general, overexpression of the sponge has few consequences and requires a cell type that expresses almost no sponge in order to observe significant effects. Usually, the sponge $\mathrm{KD}$ is done to identify RNA targets of the freed miRNA. These targets are also named secondary targets (or true targets or effector RNAs) when they control an important biological process such as proliferation, invasion, or migration.

Genome-wide analyses can be done to quantify the targets expression at the RNA level. We recommend RNA-Seq, as it detects all of the RNA, even those that are still poorly described such as lncRNA. The gene expression data can be directly downloaded on MiRonTop web tool in order to retrieve enriched targets of specific miRNAs, according to several existing miRNA target prediction approaches [107]

(http://www.genomique.info:8080/miRonTop/index).

In theory, several secondary targets should be find since a miRNA strongly affects the expression of a few RNAs, and only some of these have a major role in the biological processes mentioned above. Therefore, when the sponge KD is performed, there is a cascade effect: the miRNA freed from the sponge reaches several RNA targets (Fig. 4.). It is even possible that a sponge sequesters two or three different miRNA like the circHIPK3 does $[24,28]$.

It is important to confirm the direct effect of a miRNA on its secondary targets in the model of interest. This additional experiment consists of overexpressing a miRNA inhibitor (like antimiR) and observing the increase expression of the effector RNA. This will work if the miRNA is partly sponged: only the free and active portion of a miRNA can be inhibited with miRNA inhibitors.

To test if the secondary targets belong to the sponge network, co-expression of the sponge RNA and the effector RNAs can be measured in the available datasets (TCGA or GEO: http://cancergenome.nih.gov/ \& http://www.ncbi.nlm.nih.gov/geo/). According to the principle of competition among RNAs, the sponge and two or more secondary RNAs must be co-regulated in tissues or tumors [16,24].

The network can be recapitulated using miRNA sensors (Fig. 3.) [106]. It is important to note that this approach highlights the activity of an endogenous quantity of miRNA. So, to observe the miRNA effect, miRNA sensors should be weakly expressed.

Advantages: Simple approach which gives robust results. Work is done on endogenous quantities of miRNA.

Disadvantages: Several siRNA targeting the sponge must be tested to avoid the off-target effects of siRNA acting as miRNA.

Potential issue: The cellular model has to be chosen according to the level of the sponge.

\section{$\underline{\text { 7. Biological and clinical relevance of RNA-sponges }}$}

\subsection{RNA-sponges and read-outs}

After the identification of the sponge, the sequestered miRNA and the secondary targets, forming the network, it is tempting to evaluate the biological significance of the sponge or ceRNA by overexpressing or inhibiting its expression in complete organisms. Pandolfi's group did this with transgenic mice overexpressing just the 3'-UTR of a ceRNA. These mice 
developed an aggressive malignancy resembling human diffuse large B cell lymphoma [67]. This in vivo demonstration of competition between RNA to bind a small regulatory RNA is not isolated, since similar competition occurred in plants and bacteria [14,22,85]. Along with these very convincing publications, we must also consider research where recognizable phenotypes have been obtained using exogenous sponges or decoys $[19,20,108]$. Together, these experiments lead us to think that the competition mechanism is possible in vivo and can induce unexpected biological consequences.

\subsection{Can we go further?}

Without a doubt, yes, using new transgenic mice or other models such as Drosophila, zebrafish, and Xenopus. Furthermore, CRISPR/Cas9 technology will convert a sponge into a simple miRNA target by modifying the MRE [109]. It is interesting to note that the CRISPR Synergistic Activation Mediator (SAM) is particularly suitable for increasing the quantity of a miRNA sponge or the expression of a miRNA. SAM is an engineered protein complex for the transcriptional activation of endogenous genes such as endogenous sponges [110]. The advantage of this method is in the nature of the overexpressed endogenous sponge and so taking into account possible SNP or RNA editing. Unfortunately, these methodologies are unwieldy in mammals, and serve principally to demonstrate a working hypothesis or mechanism.

If there is enough evidence for a sponge from a molecular and functional point of view, and if its activity is of interest (associated to a disease, treatment resistance, etc), it may be wise to try acting on the sponge to annul its adverse effects.

\subsection{Oligonucleotides to challenge the RNA competition}

The first wave of publications using Antisense Oligonucleotides (ASOs) had been before 2002 [111], when RNA interference took off, and the toxicity associated with firstgeneration ASOs limited its in vivo use $[112,113]$. Original chemical modifications making ASO stable and specific in vivo have driven the renewed interest in ASOs [114-116]. In contrast to siRNA, ASOs can be injected subcutaneously without lipid formulation, offering an acceptable distribution in tissues [117,118]. We categorize ASOs by their functions (Fig. 5.).

The most famous ASO is the drug Kynamro® that induces degradation of ApoB100 in liver of patients with familial hypercholesterolemia [119]. Once it arrived on the market, interest in short modified nucleic acid sequences resurged. This enthusiasm for RNA as a gateway to disease therapeutics can be seen in the creation of research institutes focused on this strategy, including the RNA Institute at the University of Albany, the RNA Therapeutics Institute (RTI) at UMass Medical School (Worcester), and the Institute for RNA Medicine at BIDMC Cancer Center/Harvard Medical School (Boston).

\subsubsection{Eraser ASOs}

Historically, ASOs have been designed to induce degradation on the targeted RNA. GapmeRs are highly effective ASOs, which are well-tolerated in vivo [120]. The modified nucleotides, also called locked nucleic acids (LNAs), are distributed to the GapmeR's ends and not to its center [121]. This allows for RNAse H recruitment and induces the degradation of the targeted RNA. GapmeRs therefore trigger target degradation in vivo [122,123], and this could be used to destroy miRNA sponges. 


\subsubsection{Masking ASOs}

These ASOs interfere in a precise area of the targeted RNA without inducing its degradation. This time, the LNAs are distributed all along the ASO, avoiding RNAse $\mathrm{H}$ recruitment. These masking ASOs were historically used to study splicing or translation, or to avoid RNA secondary structures. Currently, this strategy is well-developed in gene therapy trials involving exon skipping [124]. For therapy targeted miRNA sponge, masking ASOs associate with MRE and prevent sequestration of the corresponding miRNA. These ASOs are known as target site blockers (TSB, Exiqon). Some in vivo applications have been published using this innovative therapeutic strategy. They lead us to hope for rapid medical successes $[125,126]$.

\subsection{3. miRNA analogs}

This category is represented by synthetic miRNAs (also named mimic miRNAs). With these molecules, the idea is to restore miRNA activity in cells that have lost it due to deletion or methylation of the miRNA gene. This is also an interesting alternative for restoring miRNA activity through overcoming the RNA sponge's sequestration ability.

Depending on the source, these molecules are double-stranded or form a hairpin that needs Dicer cleavage to obtain the active product. Recently, Exiqon proposed an interesting new way to reduce the passenger strand effect of double-stranded RNA. They used an unmodified miRNA guide strand with a sequence exactly matching the miRBase annotation, and the passenger strand was split in two LNA-modified RNA strands complementary to the miRNA one (http://www.exiqon.com/mirna-mimics).

This mimic miRNA strategy has long been explored in treatment, but success stories are scarce in the literature. A rare published example is miR-34 (MRX34), a mimic developed by miRNA Therapeutics ${ }^{\circledR}$ and encapsulated in a liposomal nanoparticle formulation [127]. It inhibits multiple oncogenic pathways and stimulates anti-tumor immune responses to induce cancer cell death [128]. The company determined the maximum-tolerated dose of MRX34, and specified the recommended dose for future clinical trials. Mirna Therapeutics plans to provide a clinical update on their Phase I miR-34 study in mid-2016 (ClinicalTrials.gov Identifier: NCT01829971), and top-line data in mid-2017.

\subsubsection{Anti-miRNA ASOs}

These anti-miRNA ASOs (or miRNA inhibitors) are 100\% complementary to their miRNA, preventing their biological activity. Suppliers offer ASOs that have been chemically modified on the LNA base or its equivalent in order to promote in vivo bioavailability and nuclease resistance [117].

Here again we are in the first clinical trials. The most well-known example is Miravirsen ${ }^{\circledR}$, which treats Hepatitis $C$ virus [129]. It inhibits miR-122 by hybridizing with it, preventing stabilization of the $H C V$ RNA by two miR-122 molecules and thus hindering amplification [64]. Interestingly, final Phase IIa results show dose-dependent, prolonged antiviral activity in Hepatitis C patients [130].

An anti-miRNA strategy is an original way to block the effects of a pro-tumoral miRNA such as miR-155, which is overexpressed in a variety of malignant tumors [131].

\section{Looking to the future}


We do not yet totally understand how RNAs can enter into competition for binding small regulatory RNA such as miRNA. However, a number of publications show, even if sometimes incompletely, how miRNA can be sequestered on RNAs and thus decreased miRNA activity. As with physical loss of miRNA, this loss of function due to miRNA sequestration leads to abnormal gene expression and inevitably to the deregulation of biological processes. It is currently difficult to identify miRNA sponges or to demonstrate their biological roles. In this review we proposed complementary experiments to identify miRNA sponge existence and to inhibit them.

Despite a lack of full understanding of the competition between RNAs to bind small regulatory RNA, testing has already been done on methods for restoring miRNA activity. Interestingly, some of these strategies are being used in clinical trials. Therapeutic oligonucleotides will offer new avenues for treatments involving the targeting of miRNA sponges. RNA is also linked to a great number of pathologies that do not involve miRNAs. ASOs do also provide strategies for pathologies tied to the expression of non-coding RNA such as the lncRNA SAMMSON in melanoma [123].

RNA now have an important place in biological processes and can no longer be considered as just simple intermediaries between genes and proteins. Small regulatory RNA offers new research areas with promising medical applications.

Table 1: Characteristics of endogenous RNAs able to bind miRNAs

\begin{tabular}{llll}
\hline RNA features & ceRNA & circRNA & spRNA \\
\hline miRNA-induced RNA Decay & YES & NO & NO \\
Long-term miRNA Sequestration & NO & YES & YES \\
Canonical MREs & YES & YES & NO \\
Linear RNA & YES & NO & YES \\
\hline
\end{tabular}

ceRNA: competing endogenous RNA

circRNA: circular RNA

spRNA: endogenous sponge RNA

MRE: miRNA response element 
Table 2: Characteristics of prokaryotic sRNA sponges/decoys

\begin{tabular}{|c|c|c|c|c|c|c|c|}
\hline sRNA decoy & Biological function & $\begin{array}{l}\text { Trapped } \\
\text { sRNA }\end{array}$ & $\begin{array}{l}\text { Derepressed } \\
\text { target }\end{array}$ & Particularity & $\begin{array}{l}\text { In Eukaryotes, } \\
\text { similarity with }\end{array}$ & Bacterial species & Ref. \\
\hline IGR of $\operatorname{chbBC}$ mRNA & Chitosugar import & ChiX & $\begin{array}{l}\text { chiP mRNA } \\
\text { chbBCARFG } \\
\text { mRNA }\end{array}$ & $\begin{array}{l}\text { Co-regulation of chiP } \\
\text { and } c h b B C A R F G \\
\text { mRNAs by ChiX } \\
\text { ChiX degradation by } \\
\text { the sRNA decoy in } \\
\text { presence of chitobiose }\end{array}$ & ceRNA & $\begin{array}{l}\text { Escherichia coli } \\
\text { and Salmonella } \\
\text { enterica } \\
\text { Thyphimurium }\end{array}$ & $\begin{array}{l}82 \\
83 \\
84\end{array}$ \\
\hline $\begin{array}{l}\text { AgvB sRNA } \\
\text { (encoded from } \\
\text { pathogenicity islands) }\end{array}$ & $\begin{array}{l}\text { Bacterial } \\
\text { colonization of } \\
\text { specific host/niche }^{1}\end{array}$ & GcvB & $\begin{array}{l}\text { Ectopic } d p p A \\
\text { mRNA }\end{array}$ & $\begin{array}{l}\text { Sequestration by the } \\
\text { sRNA sponge } \\
\text { Bacteriophage- } \\
\text { encoded sRNA } \\
\text { sponge }\end{array}$ & cvhRNAs & EHEC & 86 \\
\hline $\begin{array}{l}\text { SroC sRNA } \\
\text { (produced from the 3'- } \\
\text { UTR of the } \text { gltI mRNA) }\end{array}$ & $\begin{array}{l}\text { Adaptation to } \\
\text { nutrient availability }\end{array}$ & GcvB & $\begin{array}{l}\text { gltIJKL mRNA } \\
\text { and other ABC } \\
\text { transporters- } \\
\text { encoded mRNA }\end{array}$ & $\begin{array}{l}\text { GcvB degradation by } \\
\text { the sRNA decoy }\end{array}$ & TDMD & $\begin{array}{l}\text { Salmonella } \\
\text { enterica } \\
\text { Thyphimurium }\end{array}$ & 85 \\
\hline $\begin{array}{l}\text { 3'ETS }^{\text {leuZ }} \\
\text { (3' external transcribed } \\
\text { spacer of leuZ pre- } \\
\text { tRNA) }\end{array}$ & $\begin{array}{l}\text { Transcriptional noise } \\
\text { prevention from } \\
\text { repressed sRNAs }\end{array}$ & RhyB & $\begin{array}{l}\text { Non-essen- tial } \\
\text { Fe-using proteins- } \\
\text { encoded mRNAs }\end{array}$ & $\begin{array}{l}\text { Sequestration of the } \\
\text { sRNAs by the } \\
\text { 3'ETS }\end{array}$ & miRNA sponge & Escherichia coli & 22 \\
\hline
\end{tabular}

${ }^{1}$ Predictive biological function; ${ }^{2}$ gltIJKL mRNA degradation by GcvB produced SroC

IGR: intergenic region; ceRNA: competing endogenous RNA; TDMD: target RNA-directed miRNA degradation; EHEC: Enterohemorragic Escherichia coli; cvhRNAs: competitive viral and host RNAs 


\section{FIGURE LEGENDS}

Fig. 1.: Sponge RNAs sequester small RNAs (miRNA or sRNA) in different models. In Arabidopsis Thaliana, miR399 stimulates mRNA decay of PHO2 (Phosphate 2). When the long non-coding IPS1 (Induced by Phosphate Starvation 1) RNA is overexpressed, it binds miR399 but the mismatch between IPS1 and miR399 prevents the cleavage of IPS1. The miR399 is thus sequestered on IPS1, leading to the derepression of PHO2 mRNA, which prevents the Phosphate inorganic (Pi) toxicity (increase, see arrow on the cartoon). miR-122 determines the expression levels of many mRNAs in hepatocyte. In Hepatitis C Virus-infected hepatocytes, the miR-122 binds to $H C V$ RNA allowing the viral RNA stability and replication. By this way, $H C V$ sequesters miR-122 and deregulates expression level of mRNA host genes also favouring the $H C V$ replication cycle.

In mammals, miR-124 regulates the expression levels of many mRNAs in hepatoma cells such as DLX2 (Distal-Less Homeobox 2) mRNA. When the circular RNA circHIPK3 derived from HIPK3 mRNA is expressed, it sequesters miR-124 (and 8 other miRNAs). Thus, the expression of $D L X 2$ is derepressed in hepatoma cells.

In enterohemorrhagic Escherichia coli, GcvB sRNA represses expression level of $d p p A$ mRNA. AgvB, a bacteriophage-encoded anti-sRNA, antagonized the function of GcvB, by mimicking its mRNA substrate sequence. The GcvB loss of function gives a growth advantage specifically in bovine rectal mucus.

Fig. 2.: Experimental workflow to identify and validate miRNA sponges.

The workflow proposes three ways to identify the miRNA sponge or the sequestered miRNA on the sponge. Strategies are based on purification from a bait (as 3'-UTR fused with MS2 motif or biotinylated miRNA) or a genome-wide methodology (as iCLIP). Different approaches are available to identify and quantify the candidate (see main text). The last step consists to validate the sponge's resistance to miRNA-induced decay and to confirm the sponge network' participants.

Fig. 3.: Evaluation of miRNA's activity from miRNAs released from a sponge. The sponge knock down leads to the release of endogenous miRNAs docked on the sponge RNA. Freed miRNAs are redirected to miRNA sensors, which consist of the canonical or non-canonical MRE sequence (from a secondary target or the sponge, respectively) fused to the luciferase ORF. In presence of the canonical MRE (wild-type (WT) sensor), freed miRNAs reduce the luciferase activity, which is lost when this MRE is mutated (MUT sensor). Again no decrease of the luciferase activity should be seen in the presence of the noncanonical MRE (Sponge sensor). The target sensor activities are normalized against a control one (CTR sensor). MRE; miRNA Response Element, siCTR; siRNA control.

\section{Fig. 4.: Cascade effect in response to miRNA sponge depletion.}

In general, a miRNA represses many RNAs. Hence, the depletion of the sponge by RNA interference releases miRNA (new miRNA distribution) and restores a normal RNA decay of its targets (regulation of $n$ mRNAs). The phenotype observed in response to the sponge depletion is the result of a sum of RNAs decay and proteins down regulation. Sometimes, miRNA sponge also encodes a protein. We termed this phenomenon the cascade effect. The power of the cascade depends on the expression level of the sponge and the amount of the sequestered miRNA.

Fig. 5.: Strategies to restore miRNA's activity using tailored oligonucleotides. 
After the identification of the sponge and the sequestered small RNA (sRNA or miRNA), the crucial step is to demonstrate the biological relevance of these heteroduplexes. For the miRNA-sponge case, three different oligonucleotides can be used. The miRNA mimic corresponds to a synthetic miRNA transfected into the cells. The goal is to bypass the sequestration capability of the sponge by increasing the total amount of miRNAs (endogenous (sequestered + active) and synthetic) in the cell in order to restore the effector RNAs decay. Another solution to reset miRNA activity in the cell is to prevent the sequestration of the miRNA on the sponge. Thus, antisense oligonucleotides (ASOs) are designed to mask the miRNA response element on the sponge (MRE, in red). It is important to note that target site blockers (TSB) are specific for one MRE on one sponge since the TSB sequence binds a part of the MRE and a short flanking sequence. This design ensures the specificity of the TSB. The last solution consists in erasing the sponge expression using a GapmeR specific to the sponge. This ASO recruits RNAse H to destroy the sponge. In other words, GapmeRs give the same results than siRNA for cytosolic RNA. For sponge located in the nucleus, GapmeRs are more potent than siRNA.

\section{ACKNOWLEDGMENTS}

We thank Brice Felden for editorial assistance and Laura Bachelot \& Arthur Gautron for assistance with the figures and Sébastien Corre for critical reading. This study received financial support from the following: Institut National du Cancer (Melanoma PAIR program); Ouest Valorisation; Ligue Nationale Contre le Cancer (LNCC et comités Grand-Ouest); Région Bretagne; University of Rennes 1; CNRS; European Organisation for Research and Treatment of Cancer Tournesol program'; and the Société Française de Dermatologie. MM received fellowships from 'Ligue Nationale Contre le Cancer' (CD-22) and Faculty of Pharmacy of Rennes. EDF received fellowships from 'Ligue Nationale Contre le Cancer'. The authors thank the Gene Expression and Oncogenesis team for helpful discussions. The authors declare no competing financial interests.

\section{REFERENCES}

[1] J.W. Nam, O.S. Rissland, D. Koppstein, C. Abreu-Goodger, C. Jan, V. Agarwal, M.A. Yildirim, A. Rodriguez, D.P. Bartel, Global analyses of the effect of different cellular contexts on microRNA targeting, Mol. Cell. 53 (2014) 1031-1043. doi:10.1016/j.molcel.2014.02.013.

[2] A. Wilczynska, M. Bushell, The complexity of miRNA-mediated repression., Cell Death Differ. 22 (2015) 22-33. doi:10.1038/cdd.2014.112.

[3] M. Selbach, B. Schwanhäusser, N. Thierfelder, Z. Fang, R. Khanin, N. Rajewsky, Widespread changes in protein synthesis induced by microRNAs., Nature. 455 (2008) 58-63. doi:10.1038/nature07228.

[4] S.W. Eichhorn, H. Guo, S.E. McGeary, R.A. Rodriguez-Mias, C. Shin, D. Baek, S. Hsu, K. Ghoshal, J. Villén, D.P. Bartel, mRNA Destabilization Is the Dominant Effect of Mammalian MicroRNAs by the Time Substantial Repression Ensues, Mol. Cell. 56 (2014) 104-115. doi:10.1016/j.molcel.2014.08.028. 
[5] D. Baek, J. Villén, C. Shin, F.D. Camargo, S.P. Gygi, D.P. Bartel, The impact of microRNAs on protein output., Nature. 455 (2008) 64-71. doi:10.1038/nature07242.

[6] H. oki Iwakawa, Y. Tomari, The Functions of MicroRNAs: mRNA Decay and Translational Repression, Trends Cell Biol. 25 (2015) 651-665. doi:10.1016/j.tcb.2015.07.011.

[7] A. Kozomara, S. Griffiths-Jones, MiRBase: Annotating high confidence microRNAs using deep sequencing data, Nucleic Acids Res. 42 (2014). doi:10.1093/nar/gkt1181.

[8] C.Y. Park, L.T. Jeker, K. Carver-Moore, A. Oh, H.J. Liu, R. Cameron, H. Richards, Z. Li, D. Adler, Y. Yoshinaga, M. Martinez, M. Nefadov, A.K. Abbas, A. Weiss, L.L. Lanier, P.J. de Jong, J.A. Bluestone, D. Srivastava, M.T. McManus, A Resource for the Conditional Ablation of microRNAs in the Mouse, Cell Rep. 1 (2012) 385-391. doi:10.1016/j.celrep.2012.02.008.

[9] E.A. Miska, E. Alvarez-Saavedra, A.L. Abbott, N.C. Lau, A.B. Hellman, S.M. McGonagle, D.P. Bartel, V.R. Ambros, H.R. Horvitz, Most Caenorhabditis elegans microRNAs are individually not essential for development or viability, PLoS Genet. 3 (2007) 2395-2403. doi:10.1371/journal.pgen.0030215.

[10] E. Alvarez-Saavedra, H.R. Horvitz, Many Families of C. elegans MicroRNAs Are Not Essential for Development or Viability, Curr. Biol. 20 (2010) 367-373. doi:10.1016/j.cub.2009.12.051.

[11] J. Li, M. Reichel, Y. Li, A.A. Millar, The functional scope of plant microRNAmediated silencing, Trends Plant Sci. 19 (2014) 750-756. doi:10.1016/j.tplants.2014.08.006.

[12] G.B. Loeb, A.A. Khan, D. Canner, J.B. Hiatt, J. Shendure, R.B. Darnell, C.S. Leslie, A.Y. Rudensky, Transcriptome-wide miR-155 binding map reveals widespread noncanonical microRNA targeting., Mol. Cell. 48 (2012) 760-70. doi:10.1016/j.molcel.2012.10.002.

[13] G. Di Leva, M. Garofalo, C.M. Croce, MicroRNAs in cancer., Annu. Rev. Pathol. 9 (2014) 287-314. doi:10.1146/annurev-pathol-012513-104715.

[14] J.M. Franco-Zorrilla, A. Valli, M. Todesco, I. Mateos, M.I. Puga, I. Rubio-Somoza, A. Leyva, D. Weigel, J.A. García, J. Paz-Ares, Target mimicry provides a new mechanism for regulation of microRNA activity., Nat. Genet. 39 (2007) 1033-1037. doi:10.1038/ng2079.

[15] H. Seitz, Redefining microRNA targets., Curr. Biol. 19 (2009) 870-3. doi:10.1016/j.cub.2009.03.059.

[16] L. Salmena, L. Poliseno, Y. Tay, L. Kats, P.P. Pandolfi, A ceRNA hypothesis: the Rosetta Stone of a hidden RNA language?, Cell. 146 (2011) 353-8. doi:10.1016/j.cell.2011.07.014.

[17] M.S. Ebert, J.R. Neilson, P.A. Sharp, MicroRNA sponges: competitive inhibitors of small RNAs in mammalian cells., Nat. Methods. 4 (2007) 721-6. doi:10.1038/nmeth1079.

[18] A.D. Bosson, J.R. Zamudio, P.A. Sharp, Endogenous miRNA and Target Concentrations Determine Susceptibility to Potential ceRNA Competition, Mol. Cell. 56 (2014) 347-359. doi:10.1016/j.molcel.2014.09.018.

[19] M. Reichel, Y. Li, J. Li, A. a. Millar, Inhibiting plant microRNA activity: molecular SPONGEs, target MIMICs and STTMs all display variable efficacies against target microRNAs, Plant Biotechnol. J. 13 (2015) 915-26.

[20] S.A. Giusti, A.M. Vogl, M.M. Brockmann, C.A. Vercelli, M.L. Rein, D. Trümbach, W. Wurst, D. Cazalla, V. Stein, J.M. Deussing, D. Refojo, MicroRNA-9 controls dendritic development by targeting REST., Elife. 3 (2014) 1-22. doi:10.7554/eLife.02755.

[21] K.S. Fröhlich, J. Vogel, Activation of gene expression by small RNA, Curr. Opin. 
Microbiol. 12 (2009) 674-682. doi:10.1016/j.mib.2009.09.009.

[22] D. Lalaouna, M.C. Carrier, S. Semsey, J.S. Brouard, J. Wang, J. Wade, E. Massé, A 3' external transcribed spacer in a tRNA transcript acts as a sponge for small RNAs to prevent transcriptional noise, Mol. Cell. 58 (2015) 393-405. doi:10.1016/j.molcel.2015.03.013.

[23] L. Poliseno, L. Salmena, J. Zhang, B. Carver, W.J. Haveman, P.P. Pandolfi, A codingindependent function of gene and pseudogene mRNAs regulates tumour biology., Nature. 465 (2010) 1033-1038. doi:10.1038/nature09144.

[24] Y. Tay, L. Kats, L. Salmena, D. Weiss, S.M. Tan, U. Ala, F. Karreth, L. Poliseno, P. Provero, F. Di Cunto, J. Lieberman, I. Rigoutsos, P.P. Pandolfi, Coding-independent regulation of the tumor suppressor PTEN by competing endogenous mRNAs, Cell. 147 (2011) 344-357. doi:10.1016/j.cell.2011.09.029.

[25] F.A. Karreth, Y. Tay, D. Perna, U. Ala, S.M. Tan, A.G. Rust, G. Denicola, K.A. Webster, D. Weiss, P.A. Perez-Mancera, M. Krauthammer, R. Halaban, P. Provero, D.J. Adams, D.A. Tuveson, P.P. Pandolfi, In vivo identification of tumor- suppressive PTEN ceRNAs in an oncogenic BRAF-induced mouse model of melanoma, Cell. 147 (2011) 382-395. doi:10.1016/j.cell.2011.09.032.

[26] S. Memczak, M. Jens, A. Elefsinioti, F. Torti, Circular RNAs are a large class of animal RNAs with regulatory potency, Nature. 495 (2013) 333-8. doi:10.1038/nature11928.

[27] T.B. Hansen, T.I. Jensen, B.H. Clausen, J.B. Bramsen, B. Finsen, C.K. Damgaard, J. Kjems, Natural RNA circles function as efficient microRNA sponges., Nature. 495 (2013) 384-8. doi:10.1038/nature11993.

[28] Q. Zheng, C. Bao, W. Guo, S. Li, J. Chen, B. Chen, Y. Luo, D. Lyu, Y. Li, G. Shi, L. Liang, J. Gu, X. He, S. Huang, Circular RNA profiling reveals an abundant circHIPK3 that regulates cell growth by sponging multiple miRNAs, Nat. Commun. 7 (2016) 11215. doi:10.1038/ncomms11215.

[29] M. Jens, N. Rajewsky, Competition between target sites of regulators shapes posttranscriptional gene regulation., Nat. Rev. Genet. 16 (2015) 113-26. doi:10.1038/nrg3853.

[30] S. Srikantan, K. Tominaga, M. Gorospe, Functional Interplay between RNA-Binding Protein HuR and microRNAs, Curr. Protein Pept. Sci. 13 (2012) 372-379. doi:10.2174/138920312801619394.

[31] M.J. Moore, T.K.H. Scheel, J.M. Luna, C.Y. Park, J.J. Fak, E. Nishiuchi, C.M. Rice, R.B. Darnell, miRNA-target chimeras reveal miRNA 3'-end pairing as a major determinant of Argonaute target specificity., Nat. Commun. 6 (2015) 8864. doi:10.1038/ncomms9864.

[32] J.P. Broughton, A.E. Pasquinelli, A tale of two sequences: microRNA-target chimeric reads., Genet. Sel. Evol. 48 (2016) 31. doi:10.1186/s12711-016-0209-x.

[33] A. Helwak, G. Kudla, T. Dudnakova, D. Tollervey, Mapping the human miRNA interactome by CLASH reveals frequent noncanonical binding, Cell. 153 (2013) 654665. doi:10.1016/j.cell.2013.03.043.

[34] J. Imig, A. Brunschweiger, A. Brümmer, B. Guennewig, N. Mittal, S. Kishore, P. Tsikrika, A.P. Gerber, M. Zavolan, J. Hall, miR-CLIP capture of a miRNA targetome uncovers a lincRNA H19-miR-106a interaction., Nat. Chem. Biol. 11 (2015) 107-14. doi:10.1038/nchembio.1713.

[35] S. Lebedeva, M. Jens, K. Theil, B. Schwanhäusser, M. Selbach, M. Landthaler, N. Rajewsky, Transcriptome-wide Analysis of Regulatory Interactions of the RNABinding Protein HuR, Mol. Cell. 43 (2011) 340-352. doi:10.1016/j.molcel.2011.06.008. 
[36] V. Agarwal, G.W. Bell, J.-W. Nam, D.P. Bartel, Predicting effective microRNA target sites in mammalian mRNAs, Elife. 4 (2015). doi:10.7554/eLife.05005.

[37] A. Grimson, K.K.-H. Farh, W.K. Johnston, P. Garrett-Engele, L.P. Lim, D.P. Bartel, MicroRNA targeting specificity in mammals: determinants beyond seed pairing., Mol. Cell. 27 (2007) 91-105. doi:10.1016/j.molcel.2007.06.017.

[38] H.C. Martin, S. Wani, A.L. Steptoe, K. Krishnan, K. Nones, E. Nourbakhsh, A. Vlassov, S.M. Grimmond, N. Cloonan, Imperfect centered miRNA binding sites are common and can mediate repression of target mRNAs., Genome Biol. 15 (2014) R51. doi:10.1186/gb-2014-15-3-r51.

[39] S.W. Chi, G.J. Hannon, R.B. Darnell, An alternative mode of microRNA target recognition., Nat. Struct. Mol. Biol. 19 (2012) 321-7. doi:10.1038/nsmb.2230.

[40] M. Khorshid, J. Hausser, M. Zavolan, E. van Nimwegen, A biophysical miRNAmRNA interaction model infers canonical and noncanonical targets., Nat. Methods. 10 (2013) 253-5. doi:10.1038/nmeth.2341.

[41] S. Grosswendt, A. Filipchyk, M. Manzano, F. Klironomos, M. Schilling, M. Herzog, E. Gottwein, N. Rajewsky, Unambiguous Identification of miRNA: Target site interactions by different types of ligation reactions, Mol. Cell. 54 (2014) 1042-1054. doi:10.1016/j.molcel.2014.03.049.

[42] D.W. Thomson, M.E. Dinger, Endogenous microRNA sponges: evidence and controversy, Nat. Rev. Genet. 17 (2016) 272-283. doi:10.1038/nrg.2016.20.

[43] Y. Tay, J. Rinn, P.P. Pandolfi, The multilayered complexity of ceRNA crosstalk and competition., Nature. 505 (2014) 344-52. doi:10.1038/nature12986.

[44] P. Xie, Y. Liu, Y. Li, M.Q. Zhang, X. Wang, MIROR: a method for cell-type specific microRNA occupancy rate prediction., Mol. Biosyst. 10 (2014) 1377-84. doi:10.1039/c3mb70610a.

[45] R. Denzler, V. Agarwal, J. Stefano, D.P. Bartel, M. Stoffel, Assessing the ceRNA hypothesis with quantitative measurements of miRNA and target abundance, Mol. Cell. 54 (2014) 766-776.

[46] I. López de Silanes, M. Zhan, A. Lal, X. Yang, M. Gorospe, Identification of a target RNA motif for RNA-binding protein HuR., Proc. Natl. Acad. Sci. U. S. A. 101 (2004) 2987-2992. doi:10.1073/pnas.0306453101.

[47] N. Mukherjee, D.L. Corcoran, J.D. Nusbaum, D.W. Reid, S. Georgiev, M. Hafner, M. Ascano, T. Tuschl, U. Ohler, J.D. Keene, Integrative Regulatory Mapping Indicates that the RNA-Binding Protein HuR Couples Pre-mRNA Processing and mRNA Stability, Mol. Cell. 43 (2011) 327-339. doi:10.1016/j.molcel.2011.06.007.

[48] J. Kim, K. Abdelmohsen, X. Yang, S. De, I. Grammatikakis, J.H. Noh, M. Gorospe, LncRNA OIP5-AS1/cyrano sponges RNA-binding protein HuR, Nucleic Acids Res. 44 (2016) 2378-2392. doi:10.1093/nar/gkw017.

[49] J. Konig, K. Zarnack, G. Rot, T. Curk, M. Kayikci, B. Zupan, D.J. Turner, N.M. Luscombe, J. Ule, iCLIP--transcriptome-wide mapping of protein-RNA interactions with individual nucleotide resolution., J. Vis. Exp. (2011) 1-7. doi:10.3791/2638.

[50] I. Huppertz, J. Attig, A. D’Ambrogio, L.E. Easton, C.R. Sibley, Y. Sugimoto, M. Tajnik, J. König, J. Ule, iCLIP: protein-RNA interactions at nucleotide resolution., Methods. 65 (2014) 274-87. doi:10.1016/j.ymeth.2013.10.011.

[51] M.S. Ebert, P. a. Sharp, Emerging roles for natural microRNA sponges, Curr. Biol. 20 (2010) R858-R861. doi:10.1016/j.cub.2010.08.052.

[52] M.S. Ebert, P.A. Sharp, MicroRNA sponges: progress and possibilities., RNA. 16 (2010) 2043-2050. doi:10.1261/rna.2414110.

[53] D. Bonci, V. Coppola, M. Musumeci, A. Addario, R. Giuffrida, L. Memeo, L. D’Urso, A. Pagliuca, M. Biffoni, C. Labbaye, M. Bartucci, G. Muto, C. Peschle, R. De Maria, 
The miR-15a-miR-16-1 cluster controls prostate cancer by targeting multiple oncogenic activities., Nat. Med. 14 (2008) 1271-1277. doi:10.1038/nm.1880.

[54] A.A. Millar, P.M. Waterhouse, Plant and animal microRNAs: Similarities and differences, Funct. Integr. Genomics. 5 (2005) 129-135. doi:10.1007/s10142-0050145-2.

[55] S. Mukherji, M.S. Ebert, G.X.Y. Zheng, J.S. Tsang, P.A. Sharp, A. van Oudenaarden, MicroRNAs can generate thresholds in target gene expression., Nat. Genet. 43 (2011) 854-859. doi:10.1038/ng.905.

[56] E. Levine, T. Hwa, Small RNAs establish gene expression thresholds., Curr. Opin. Microbiol. 11 (2008) 574-9. doi:10.1016/j.mib.2008.09.016.

[57] N.E. Buchler, M. Louis, Molecular titration and ultrasensitivity in regulatory networks., J. Mol. Biol. 384 (2008) 1106-19. doi:10.1016/j.jmb.2008.09.079.

[58] R.C. Brewster, F.M. Weinert, H.G. Garcia, D. Song, M. Rydenfelt, R. Phillips, The transcription factor titration effect dictates level of gene expression., Cell. 156 (2014) 1312-23. doi:10.1016/j.cell.2014.02.022.

[59] F.A. Karreth, P.P. Pandolfi, CeRNA cross-talk in cancer: When ce-bling rivalries go awry, Cancer Discov. 3 (2013) 1113-1121. doi:10.1158/2159-8290.CD-13-0202.

[60] J.A. Broderick, P.D. Zamore, Competitive Endogenous RNAs Cannot Alter MicroRNA Function InVivo, Mol. Cell. 54 (2014) 711-713. doi:10.1016/j.molcel.2014.05.023.

[61] L. Poliseno, P.P. Pandolfi, PTEN ceRNA networks in human cancer, Methods. 77-78 (2015) 41-50. doi:10.1016/j.ymeth.2015.01.013.

[62] Y. Pei, T. Tuschl, On the art of identifying effective and specific siRNAs., Nat. Methods. 3 (2006) 670-6. doi:10.1038/nmeth911.

[63] D. Cazalla, T. Yario, J.A. Steitz, Down-regulation of a host microRNA by a Herpesvirus saimiri noncoding RNA., Science. 328 (2010) 1563-1566. doi:10.1126/science. 1187197.

[64] J.M. Luna, T.K.H. Scheel, T. Danino, K.S. Shaw, A. Mele, J.J. Fak, E. Nishiuchi, C.N. Takacs, M.T. Catanese, Y.P. de Jong, I.M. Jacobson, C.M. Rice, R.B. Darnell, Hepatitis C Virus RNA Functionally Sequesters miR-122, Cell. 160 (2015) 1099-1110. doi:10.1016/j.cell.2015.02.025.

[65] Y. Li, T. Masaki, D. Yamane, D.R. McGivern, S.M. Lemon, Competing and noncompeting activities of miR-122 and the 5' exonuclease Xrn1 in regulation of hepatitis C virus replication., Proc. Natl. Acad. Sci. U. S. A. 110 (2013) 1881-6. doi:10.1073/pnas.1213515110.

[66] C. Li, J. Hu, J. Hao, B. Zhao, B. Wu, L. Sun, S. Peng, G.F. Gao, S. Meng, Competitive virus and host RNAs: The interplay of a hidden virus and host interaction, Protein Cell. 5 (2014) 348-356. doi:10.1007/s13238-014-0039-y.

[67] F.A. Karreth, M. Reschke, A. Ruocco, C. Ng, B. Chapuy, V. Léopold, M. Sjoberg, T.M. Keane, A. Verma, U. Ala, Y. Tay, D. Wu, N. Seitzer, M.D.C. Velasco-Herrera, A. Bothmer, J. Fung, F. Langellotto, S.J. Rodig, O. Elemento, M.A. Shipp, D.J. Adams, R. Chiarle, P.P. Pandolfi, The BRAF pseudogene functions as a competitive endogenous RNA and induces lymphoma in vivo., Cell. 161 (2015) 319-32. doi:10.1016/j.cell.2015.02.043.

[68] T.B. Hansen, J. Kjems, C.K. Damgaard, Circular RNA and miR-7 in Cancer, Cancer Res. 73 (2013) 5609-5612. doi:10.1158/0008-5472.CAN-13-1568.

[69] D.K.-S. Yip, I.K. Pang, K.Y. Yip, Systematic exploration of autonomous modules in noisy microRNA-target networks for testing the generality of the ceRNA hypothesis., BMC Genomics. 15 (2014) 1178. doi:10.1186/1471-2164-15-1178.

[70] H.-S. Chiu, D. Llobet-Navas, X. Yang, W.-J. Chung, A. Ambesi-Impiombato, A. Iyer, 
H.R. Kim, E.G. Seviour, Z. Luo, V. Sehgal, T. Moss, Y. Lu, P. Ram, J. Silva, G.B. Mills, A. Califano, P. Sumazin, Cupid: simultaneous reconstruction of microRNAtarget and ceRNA networks., Genome Res. 25 (2015) 257-67. doi:10.1101/gr.178194.114.

[71] Z. Du, T. Sun, E. Hacisuleyman, T. Fei, X. Wang, M. Brown, J.L. Rinn, M.G.-S. Lee, Y. Chen, P.W. Kantoff, X.S. Liu, Integrative analyses reveal a long noncoding RNAmediated sponge regulatory network in prostate cancer., Nat. Commun. 7 (2016) 10982. doi:10.1038/ncomms10982.

[72] J. Hausser, M. Zavolan, Identification and consequences of miRNA-target interactions - beyond repression of gene expression., Nat. Rev. Genet. 15 (2014) 599-612. doi:10.1038/nrg3765.

[73] J. Breda, A.J. Rzepiela, R. Gumienny, E. van Nimwegen, M. Zavolan, Quantifying the strength of miRNA-target interactions., Methods. 85 (2015) 90-9. doi:10.1016/j.ymeth.2015.04.012.

[74] S. Vasudevan, Y. Tong, J.A. Steitz, Switching from Repression to Activation : MicroRNAs Can Up-regulate Translation, Science (80-. ). 318 (2007) 1931-1934.

[75] J.U. Guo, V. Agarwal, H. Guo, D.P. Bartel, Expanded identification and characterization of mammalian circular RNAs., Genome Biol. 15 (2014) 409.

[76] M. de la Mata, D. Gaidatzis, M. Vitanescu, M.B. Stadler, C. Wentzel, P. Scheiffele, W. Filipowicz, H. Großhans, Potent degradation of neuronal miRNAs induced by highly complementary targets., EMBO Rep. 16 (2015) 500-11. doi:10.15252/embr.201540078.

[77] G. Haas, S. Cetin, M. Messmer, B. Chane-Woon-Ming, O. Terenzi, J. Chicher, L. Kuhn, P. Hammann, S. Pfeffer, Identification of factors involved in target RNAdirected microRNA degradation., Nucleic Acids Res. 44 (2016) 2873-87. doi:10.1093/nar/gkw040.

[78] L.S. Waters, G. Storz, Regulatory RNAs in Bacteria, Cell. 136 (2009) 615-628. doi:10.1016/j.cell.2009.01.043.

[79] J. Babski, L.-K. Maier, R. Heyer, K. Jaschinski, D. Prasse, D. Jäger, L. Randau, R.A. Schmitz, A. Marchfelder, J. Soppa, Small regulatory RNAs in Archaea., RNA Biol. 11 (2014) 484-493. doi:10.4161/rna.28452.

[80] E.G.H. Wagner, P. Romby, Small RNAs in Bacteria and Archaea: Who They Are, What They Do, and How They Do It, Elsevier Ltd, 2015. doi:10.1016/bs.adgen.2015.05.001.

[81] A.A. Rasmussen, J. Johansen, J.S. Nielsen, M. Overgaard, B. Kallipolitis, P. ValentinHansen, A conserved small RNA promotes silencing of the outer membrane protein YbfM, Mol. Microbiol. 72 (2009) 566-577. doi:10.1111/j.1365-2958.2009.06688.x.

[82] N. Figueroa-Bossi, M. Valentini, L. Malleret, L. Bossi, Caught at its own game: Regulatory small RNA inactivated by an inducible transcript mimicking its target, Genes Dev. 23 (2009) 2004-2015. doi:10.1101/gad.541609.

[83] M. Overgaard, J. Johansen, J. Møller-Jensen, P. Valentin-Hansen, Switching off small RNA regulation with trap-mRNA, Mol. Microbiol. 73 (2009) 790-800. doi:10.1111/j.1365-2958.2009.06807.x.

[84] J. Plumbridge, L. Bossi, J. Oberto, J.T. Wade, N. Figueroa-Bossi, Interplay of transcriptional and small RNA-dependent control mechanisms regulates chitosugar uptake in Escherichia coli and Salmonella, Mol. Microbiol. 92 (2014) 648-658. doi:10.1111/mmi.12573.

[85] M. Miyakoshi, Y. Chao, J. Vogel, Cross talk between ABC transporter mRNAs via a target mRNA-derived sponge of the GcvB small RNA., EMBO J. 34 (2015) 14781492. doi:10.15252/embj.201490546. 
[86] J.J. Tree, S. Granneman, S.P. McAteer, D. Tollervey, D.L. Gally, Identification of Bacteriophage-Encoded Anti-sRNAs in Pathogenic Escherichia coli, Mol. Cell. 55 (2014) 199-213. doi:10.1016/j.molcel.2014.05.006.

[87] C. Bosia, A. Pagnani, R. Zecchina, Modelling Competing Endogenous RNA Networks., PLoS One. 8 (2013) e66609. doi:10.1371/journal.pone.0066609.

[88] S. Melamed, A. Peer, R. Faigenbaum-Romm, Y.E. Gatt, N. Reiss, A. Bar, Y. Altuvia, L. Argaman, H. Margalit, Global Mapping of Small RNA-Target Interactions in Bacteria., Mol. Cell. 63 (2016) 884-97. doi:10.1016/j.molcel.2016.07.026.

[89] A. Sanchez-Mejias, Y. Tay, Competing endogenous RNA networks: tying the essential knots for cancer biology and therapeutics., J. Hematol. Oncol. 8 (2015) 30. doi:10.1186/s13045-015-0129-1.

[90] A.M. Schmitt, H.Y. Chang, Long Noncoding RNAs in Cancer Pathways., Cancer Cell. 29 (2016) 452-63. doi:10.1016/j.ccell.2016.03.010.

[91] P.G. Stockley, N.J. Stonehouse, J.B. Murray, S.T.S. Goodman, S.J. Talbot, C.J. Adams, L. Liljas, K. Valegard, Probing sequence-specific RNA recognition by the bacteriophage MS2 coat protein, Nucleic Acids Res. 23 (1995) 2512-2518. doi:10.1093/nar/23.13.2512.

[92] K. Tominaga, S. Srikantan, E.K. Lee, S.S. Subaran, J.L. Martindale, K. Abdelmohsen, M. Gorospe, Competitive Regulation of Nucleolin Expression by HuR and miR-494, Mol. Cell. Biol. 31 (2011) 4219-4231. doi:10.1128/MCB.05955-11.

[93] J.H. Yoon, S. Srikantan, M. Gorospe, MS2-TRAP (MS2-tagged RNA affinity purification): Tagging RNA to identify associated miRNAs, Methods. 58 (2012) 8187. doi:10.1016/j.ymeth.2012.07.004.

[94] C.P. Corcoran, R. Rieder, D. Podkaminski, B. Hofmann, J. Vogel, Use of aptamer tagging to identify in vivo protein binding partners of small regulatory RNAs., Methods Mol. Biol. 905 (2012) 177-200. doi:10.1007/978-1-61779-949-5_11.

[95] M.-C. Carrier, D. Lalaouna, E. Massé, A game of tag: MAPS catches up on RNA interactomes., RNA Biol. 6286 (2016) 473-6. doi:10.1080/15476286.2016.1156830.

[96] P. Mestdagh, N. Hartmann, L. Baeriswyl, D. Andreasen, N. Bernard, C. Chen, D. Cheo, P. D'Andrade, M. DeMayo, L. Dennis, S. Derveaux, Y. Feng, S. FulmerSmentek, B. Gerstmayer, J. Gouffon, C. Grimley, E. Lader, K.Y. Lee, S. Luo, P. Mouritzen, A. Narayanan, S. Patel, S. Peiffer, S. Rüberg, G. Schroth, D. Schuster, J.M. Shaffer, E.J. Shelton, S. Silveria, U. Ulmanella, V. Veeramachaneni, F. Staedtler, T. Peters, T. Guettouche, L. Wong, J. Vandesompele, Evaluation of quantitative miRNA expression platforms in the microRNA quality control (miRQC) study., Nat. Methods. 11 (2014) 809-815. doi:10.1038/nmeth.3014.

[97] J.M.M. Engreitz, K. Sirokman, P. McDonel, A. a. Shishkin, C. Surka, P. Russell, S.R.R. Grossman, A.Y.Y. Chow, M. Guttman, E.S.S. Lander, RNA-RNA Interactions Enable Specific Targeting of Noncoding RNAs to Nascent Pre-mRNAs and Chromatin Sites, Cell. 159 (2014) 188-199. doi:10.1016/j.cell.2014.08.018.

[98] M. Rehmsmeier, P. Steffen, M. Hochsmann, R. Giegerich, Fast and effective prediction of microRNA/target duplexes., RNA. 10 (2004) 1507-17. doi:10.1261/rna.5248604.

[99] S.W. Chi, J.B. Zang, A. Mele, R.B. Darnell, Argonaute HITS-CLIP decodes microRNA-mRNA interaction maps., Nature. 460 (2009) 479-86. doi:10.1038/nature08170.

[100] N. Mittal, M. Zavolan, Seq and CLIP through the miRNA world., Genome Biol. 15 (2014) 202. doi:10.1186/gb4151.

[101] M. Hafner, M. Landthaler, L. Burger, M. Khorshid, J. Hausser, P. Berninger, A. Rothballer, M. Ascano, A.C. Jungkamp, M. Munschauer, A. Ulrich, G.S. Wardle, S. Dewell, M. Zavolan, T. Tuschl, Transcriptome-wide Identification of RNA-Binding 
Protein and MicroRNA Target Sites by PAR-CLIP, Cell. 141 (2010) 129-141. doi:10.1016/j.cell.2010.03.009.

[102] Y. Zhang, S. Xie, H. Xu, L. Qu, CLIP: viewing the RNA world from an RNA-protein interactome perspective., Sci. China. Life Sci. 58 (2015) 75-88. doi:10.1007/s11427014-4764-5.

[103] S.M. Tan, J. Lieberman, Capture and identification of mirna targets by biotin pulldown and RNA-seq, in: Methods Mol. Biol., 2016: pp. 211-228. doi:10.1007/978-1-49393067-8_13.

[104] V. Douchin, C. Bohn, P. Bouloc, Down-regulation of porins by a small RNA bypasses the essentiality of the regulated intramembrane proteolysis protease RseP in Escherichia coli., J. Biol. Chem. 281 (2006) 12253-9. doi:10.1074/jbc.M600819200.

[105] H.A. Vincent, J.O. Phillips, C.A. Henderson, A.J. Roberts, C.M. Stone, C.E. Mardle, L.E. Butt, D.M. Gowers, A.R. Pickford, A.J. Callaghan, An improved method for surface immobilisation of RNA: application to small non-coding RNA-mRNA pairing., PLoS One. 8 (2013) e79142. doi:10.1371/journal.pone.0079142.

[106] G. Mullokandov, A. Baccarini, A. Ruzo, A.D. Jayaprakash, N. Tung, B. Israelow, M.J. Evans, R. Sachidanandam, B.D. Brown, High-throughput assessment of microRNA activity and function using microRNA sensor and decoy libraries, Nat Methods. 9 (2012) 840-846.

[107] K. Le Brigand, K. Robbe-Sermesant, B. Mari, P. Barbry, MiRonTop: Mining microRNAs targets across large scale gene expression studies, Bioinformatics. 26 (2010) 3131-3132. doi:10.1093/bioinformatics/btq589.

[108] K. Papenfort, C.K. Vanderpool, Target activation by regulatory RNAs in bacteria, FEMS Microbiol. Rev. 39 (2015) 362-378. doi:10.1093/femsre/fuv016.

[109] P.D. Hsu, E.S. Lander, F. Zhang, Development and applications of CRISPR-Cas9 for genome engineering, Cell. 157 (2014) 1262-1278. doi:10.1016/j.cell.2014.05.010.

[110] S. Konermann, M.D. Brigham, A.E. Trevino, J. Joung, O.O. Abudayyeh, C. Barcena, P.D. Hsu, N. Habib, J.S. Gootenberg, H. Nishimasu, O. Nureki, F. Zhang, Genomescale transcriptional activation by an engineered CRISPR-Cas9 complex, Nature. 517 (2014) 583-8. doi:10.1038/nature14136.

[111] J.C. Burnett, J.J. Rossi, RNA-based therapeutics: Current progress and future prospects, Chem. Biol. 19 (2012) 60-71. doi:10.1016/j.chembiol.2011.12.008.RNAbased.

[112] T.L.H. Jason, J. Koropatnick, R.W. Berg, Toxicology of antisense therapeutics, Toxicol. Appl. Pharmacol. 201 (2004) 66-83. doi:10.1016/j.taap.2004.04.017.

[113] C.F. Bennett, E.E. Swayze, RNA targeting therapeutics: molecular mechanisms of antisense oligonucleotides as a therapeutic platform., Annu. Rev. Pharmacol. Toxicol. 50 (2010) 259-293. doi:10.1146/annurev.pharmtox.010909.105654.

[114] D. a Braasch, D.R. Corey, Locked nucleic acid (LNA): fine-tuning the recognition of DNA and RNA., Chem. Biol. 8 (2001) 1-7. doi:10.1016/S1074-5521(00)00058-2.

[115] M. Petersen, J. Wengel, LNA: A versatile tool for therapeutics and genomics, Trends Biotechnol. 21 (2003) 74-81. doi:10.1016/S0167-7799(02)00038-0.

[116] E.E. Swayze, A.M. Siwkowski, E. V. Wancewicz, M.T. Migawa, T.K. Wyrzykiewicz, G. Hung, B.P. Monia, C.F. Bennett, Antisense oligonucleotides containing locked nucleic acid improve potency but cause significant hepatotoxicity in animals, Nucleic Acids Res. 35 (2007) 687-700. doi:10.1093/nar/gkl1071.

[117] J. Elmén, M. Lindow, S. Schütz, M. Lawrence, A. Petri, S. Obad, M. Lindholm, M. Hedtjärn, H.F. Hansen, U. Berger, S. Gullans, P. Kearney, P. Sarnow, E.M. Straarup, S. Kauppinen, LNA-mediated microRNA silencing in non-human primates., Nature. 452 (2008) 896-9. doi:10.1038/nature06783. 
[118] K. Fluiter, A.L. ten Asbroek, M.B. de Wissel, M.E. Jakobs, M. Wissenbach, H. Olsson, O. Olsen, H. Oerum, F. Baas, In vivo tumor growth inhibition and biodistribution studies of locked nucleic acid (LNA) antisense oligonucleotides, Nucleic Acids Res. 31 (2003) 953-962.

[119] F.J. Raal, R.D. Santos, D.J. Blom, A.D. Marais, M.-J. Charng, W.C. Cromwell, R.H. Lachmann, D. Gaudet, J.L. Tan, S. Chasan-Taber, D.L. Tribble, J.D. Flaim, S.T. Crooke, Mipomersen, an apolipoprotein B synthesis inhibitor, for lowering of LDL cholesterol concentrations in patients with homozygous familial hypercholesterolaemia: a randomised, double-blind, placebo-controlled trial., Lancet (London, England). 375 (2010) 998-1006. doi:10.1016/S0140-6736(10)60284-X.

[120] C. Wahlestedt, P. Salmi, L. Good, J. Kela, T. Johnsson, T. Hökfelt, C. Broberger, F. Porreca, J. Lai, K. Ren, M. Ossipov, A. Koshkin, N. Jakobsen, J. Skouv, H. Oerum, M.H. Jacobsen, J. Wengel, Potent and nontoxic antisense oligonucleotides containing locked nucleic acids, Proc. Natl. Acad. Sci. U. S. A. 97 (2000) 5633-5638. doi:10.1073/pnas.97.10.5633.

[121] R. Stanton, S. Sciabola, C. Salatto, Y. Weng, D. Moshinsky, J. Little, E. Walters, J. Kreeger, D. DiMattia, T. Chen, T. Clark, M. Liu, J. Qian, M. Roy, R. Dullea, Chemical modification study of antisense gapmers., Nucleic Acid Ther. 22 (2012) 344-59. doi:10.1089/nat.2012.0366.

[122] L. Meng, A.J. Ward, S. Chun, C.F. Bennett, A.L. Beaudet, F. Rigo, Towards a therapy for Angelman syndrome by targeting a long non-coding RNA, Nature. (2014). doi:10.1038/nature13975.

[123] E. Leucci, R. Vendramin, M. Spinazzi, P. Laurette, M. Fiers, J. Wouters, E. Radaelli, S. Eyckerman, C. Leonelli, K. Vanderheyden, A. Rogiers, E. Hermans, P. Baatsen, S. Aerts, F. Amant, S. Van Aelst, J. van den Oord, B. de Strooper, I. Davidson, D.L.J. Lafontaine, K. Gevaert, J. Vandesompele, P. Mestdagh, J.-C. Marine, Melanoma addiction to the long non-coding RNA SAMMSON, Nature. 531 (2016) 518-522. doi:10.1038/nature17161.

[124] A. Nakamura, S. Takeda, Exon-skipping therapy for Duchenne muscular dystrophy, Lancet. 378 (2011) 546-547. doi:10.1016/S0140-6736(11)61028-3.

[125] P. Hartmann, Z. Zhou, L. Natarelli, Y. Wei, M. Nazari-Jahantigh, M. Zhu, J. Grommes, S. Steffens, C. Weber, A. Schober, Endothelial Dicer promotes atherosclerosis and vascular inflammation by miRNA-103-mediated suppression of KLF4., Nat. Commun. 7 (2016) 10521. doi:10.1038/ncomms10521.

[126] A. Messina, F. Langlet, K. Chachlaki, J. Roa, S. Rasika, N. Jouy, S. Gallet, F. Gaytan, J. Parkash, M. Tena-Sempere, P. Giacobini, V. Prevot, A microRNA switch regulates the rise in hypothalamic GnRH production before puberty., Nat. Neurosci. 19 (2016) 835-44. doi:10.1038/nn.4298.

[127] M. Agostini, R.A. Knight, miR-34: from bench to bedside., Oncotarget. 5 (2014) 87281. doi:1825 [pii].

[128] M.S. Beg, M. Borad, J. Sachdev, D.S. Hong, S. Smith, A. Bader, J. Stoudemire, S. Kim, A. Brenner, Abstract CT327: Multicenter phase I study of MRX34, a first-inclass microRNA miR-34 mimic liposomal injection, Cancer Res. 74 (2014) CT327CT327. doi:10.1158/1538-7445.AM2014-CT327.

[129] M.H. Van Der Ree, A.J. Van Der Meer, J. De Bruijne, R. Maan, A. Van Vliet, T.M. Welzel, S. Zeuzem, E.J. Lawitz, M. Rodriguez-Torres, V. Kupcova, A. WiercinskaDrapalo, M.R. Hodges, H.L.A. Janssen, H.W. Reesink, Long-term safety and efficacy of microRNA-targeted therapy in chronic hepatitis C patients, Antiviral Res. 111 (2014) 53-59. doi:10.1016/j.antiviral.2014.08.015.

[130] H.L. Janssen, H.W. Reesink, E.J. Lawitz, S. Zeuzem, M. Rodriguez-Torres, K. Patel, 
A.J. van der Meer, A.K. Patick, A. Chen, Y. Zhou, R. Persson, B.D. King, S.

Kauppinen, A.A. Levin, M.R. Hodges, Treatment of HCV infection by targeting microRNA, N Engl J Med. 368 (2013) 1685-1694. doi:10.1056/NEJMoa1209026.

[131] Y. Zhang, A.M. Roccaro, C. Rombaoa, L. Flores, S. Obad, S.M. Fernandes, A. Sacco, Y. Liu, H. Ngo, P. Quang, A.K. Azab, F. Azab, P. Maiso, M. Reagan, J.R. Brown, T.H. Thai, S. Kauppinen, I.M. Ghobrial, LNA-mediated anti-miR-155 silencing in lowgrade B-cell lymphomas, Blood. 120 (2012) 1678-1686. doi:10.1182/blood-2012-02410647. 


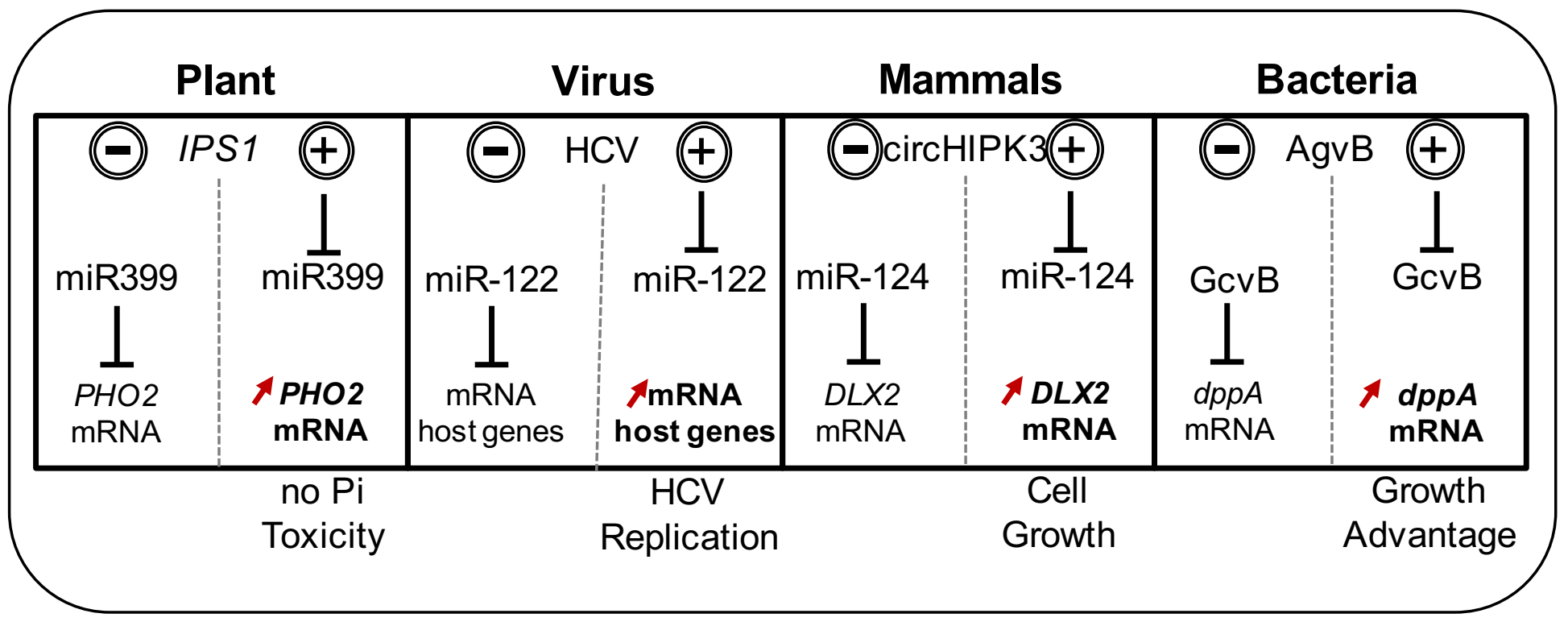

Figure 1 


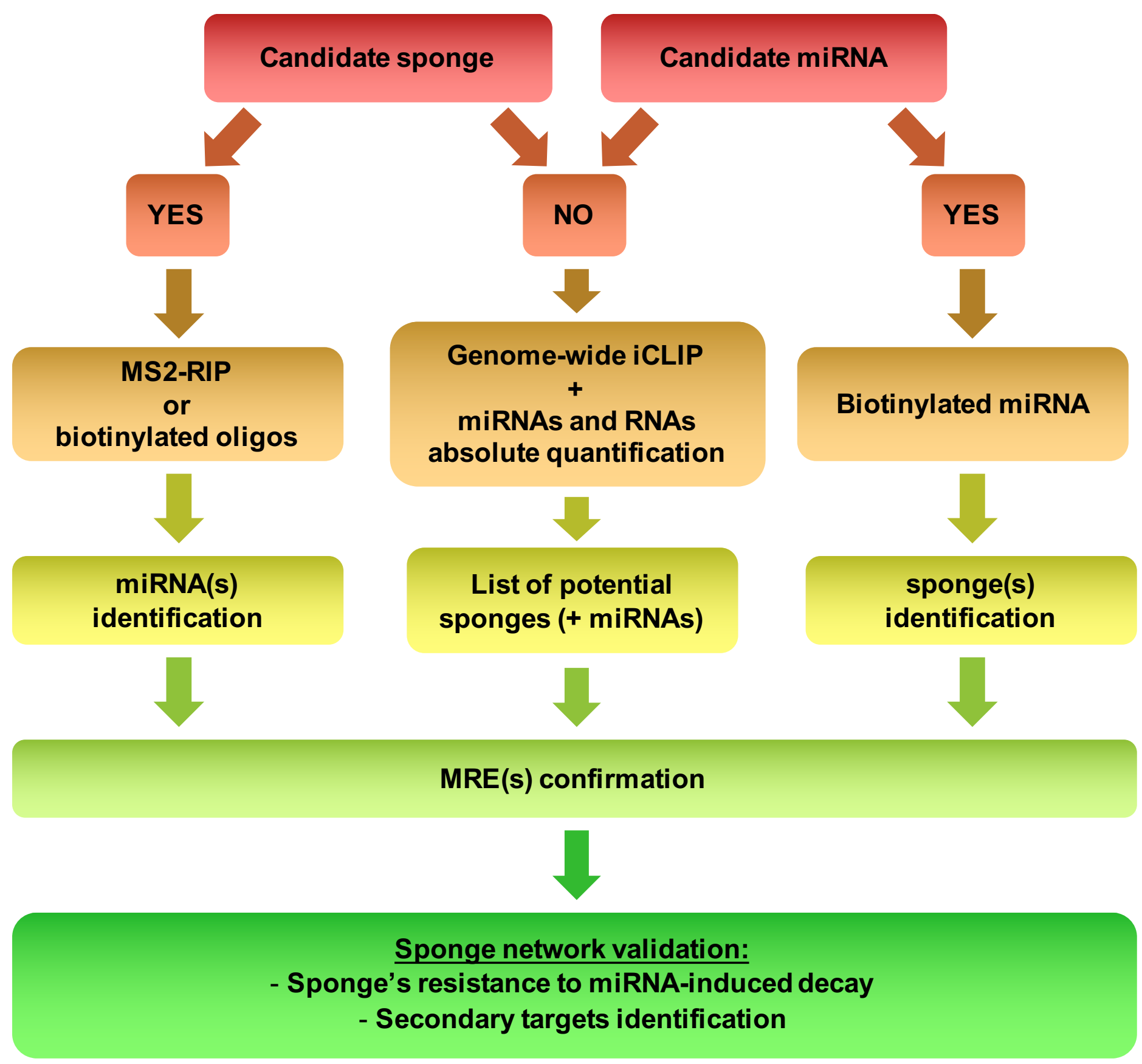

Figure 2 


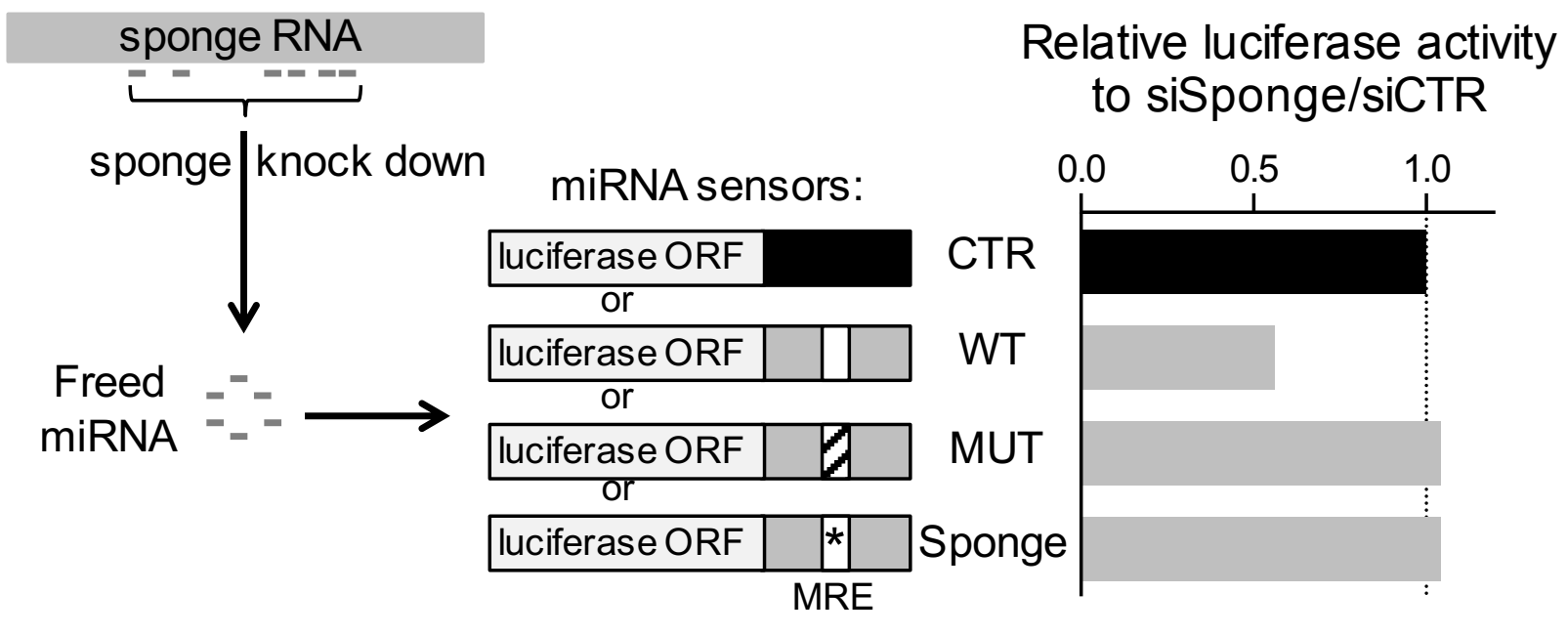

Figure 3 


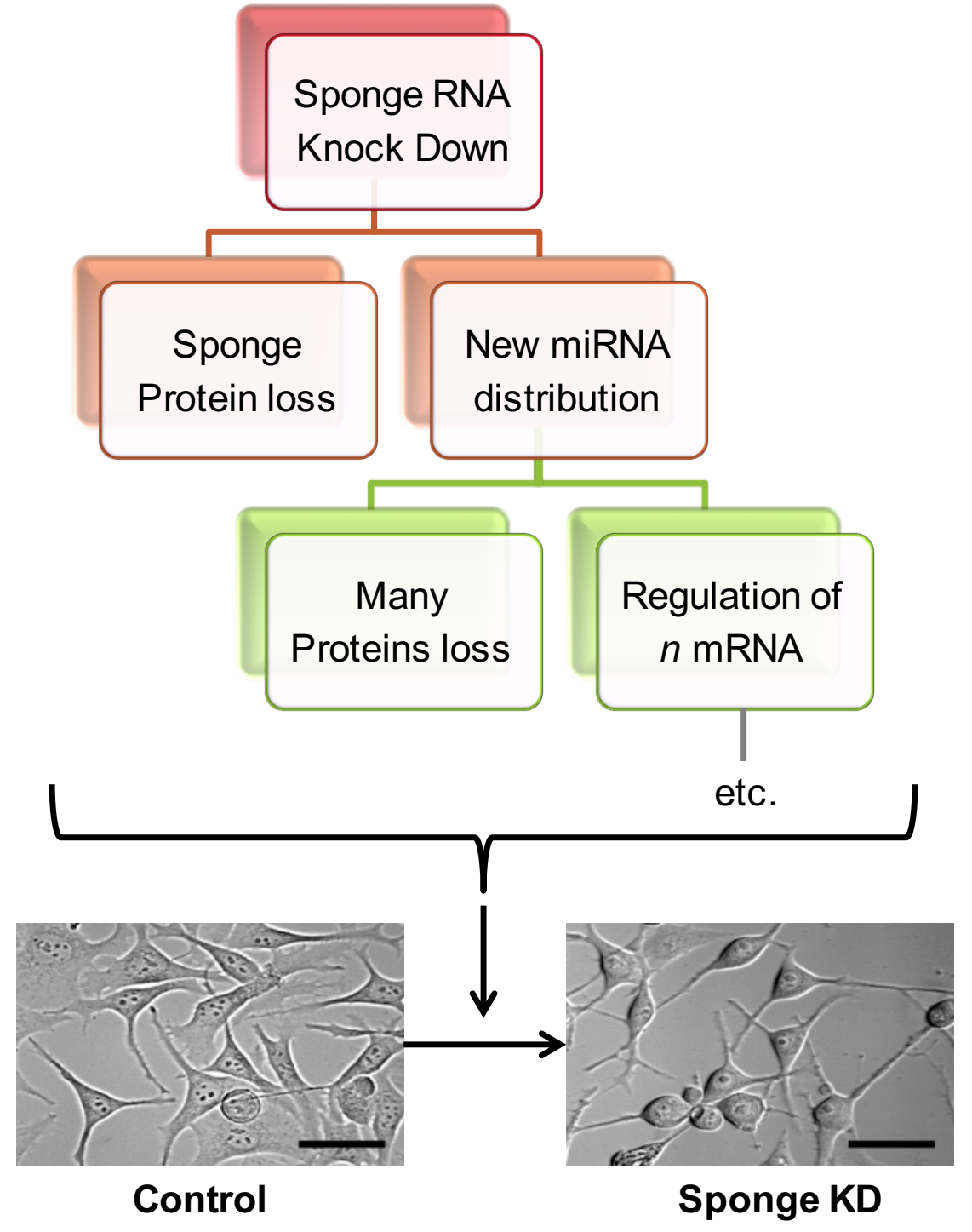

Figure 4 


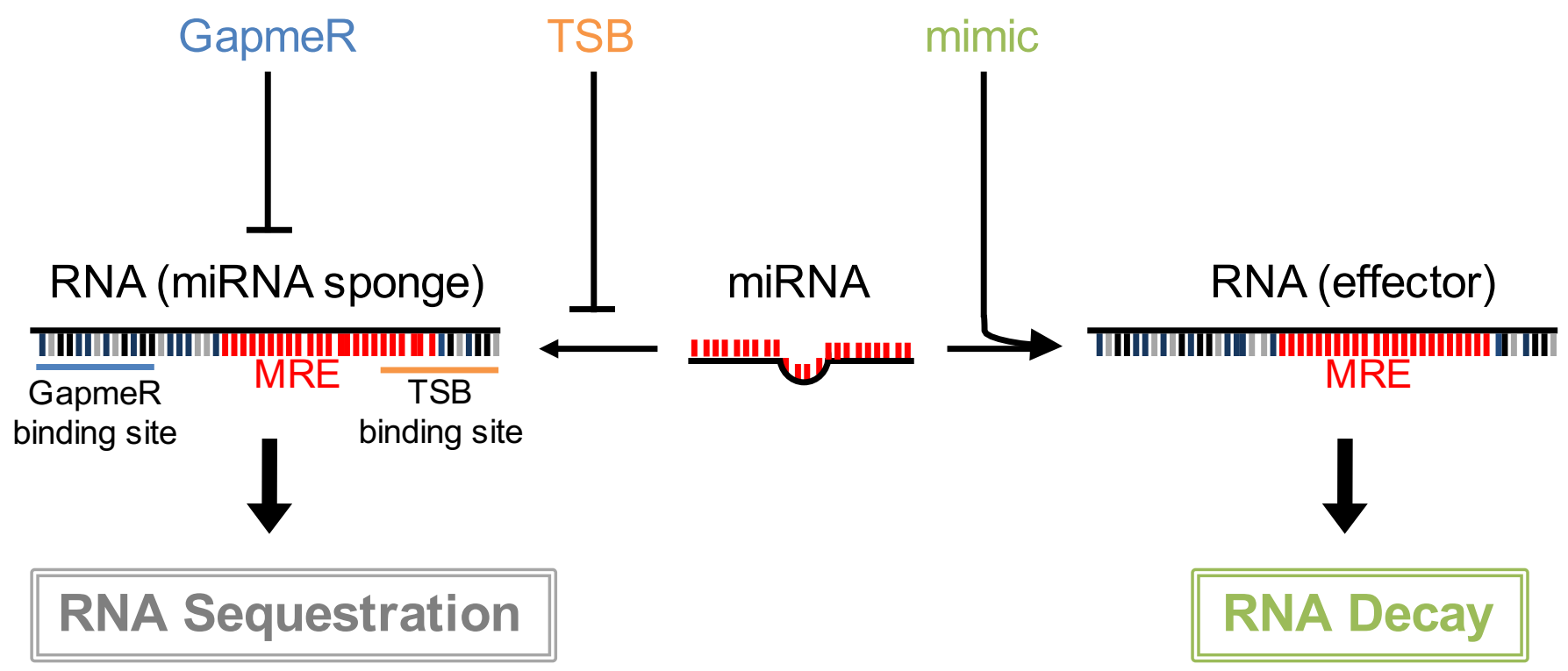

Figure 5 


\section{HIGHLIGHTS}

- An overview of RNAs competition to bind small RNAs is given.

- State of the art methods for small RNA sponge are reviewed.

- Approaches to challenge sponge activity are introduced and discussed. 